Año LII urtea

N. ${ }^{\circ}$ 94. zk.

2020

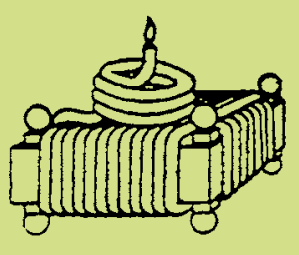

\section{CUADERNOS de Etnología y Etnografía de Navarra}

SEPARATA

\title{
Aralar mugarriturik (1523-1857)
}

Jose Luis Erdozia Mauleon 


\section{Sumario / Aurkibidea}

\section{Cuadernos de Etnología y Etnografía de Navarra}

Año LII urtea - N. ${ }^{\circ}$ 94. zk. - 2020

\section{ARTÍCULOS/ARTIKULUAK}

Etxe izen zizelkatuak. Ageriko idazkunak etxeetan eta hilobietan

Koldo Colomo Castro

Recardera, oficio de mujer

Ricardo Gurbindo Gil

Aralar mugarriturik (1523-1857)

Jose Luis Erdozia Mauleon

El lecayo, una soka-dantza del siglo XVI

Ricardo Urrizola Hualde

El recuerdo público de una muerte política: historiografía periodística y etnografía de la ritualidad pública (José Luis Cano Pérez, 1949-1977)

Kepa Fernández de Larrinoa, Karlos Irujo Asurmendi, Santiago Martínez Magdalena, Txuri Ollo Gorriti, Cristina Saura Blanco

El Camino de Santiago en Navarra en 1971 a la luz de un informe para su mejora elaborado por la Dirección de Turismo, Bibliotecas y Cultura Popular Fernando Vega López

Reformulación del discurso significativo sociocultural en el entramado fortificado de la Línea P (Valle de Roncal-Navarra) 


\section{Sumario / Aurkibidea}

NOTICIAS/BERRIAK

Joxe Ulibarrena y su pasión por la Etnografía

Elur Ulibarrena Herce

Normas para la presentación de originales / Idazlanak aurkezteko arauak / 


\title{
Aralar mugarriturik (1523-1857)
}

\author{
Amojonamiento de Aralar (1523-1857)
}

The marking of Aralar (1523-1857)

Jose Luis ERdoZIA MAULEON

Geografia eta Historian lizentziaduna eta Euskal Filologian doktorea

erdoziamauleon@gmail.com

DOI: https://doi.org/10.35462/CEEN94.3 


\section{LABURPENA}

Aralar mendiaren eremua noiz eta nola mugarritu zen jaso da artikulu honetan, Etxarri Aranazko udaletxeko artxiboan dauden bi dokumentutan oinarriturik: 1523. urtekoa lehena, Gipuzkoari ematen zaion eremua mugarritzen duena (osoaren herena, gutxi gorabehera); eta $1857 \mathrm{koa}$ bigarrena, Nafarroari ematen zaion eremuko mugarriak jasotzen dituena (osoaren bi heren). Mugarritzeen inguruko zertzeladak ere (baldintzak, ekaiak, deskribapena, parte-hartzaileak) aipatu dira artikuluan, eta baita bi dokumentuetan ageri diren toponimoak aztertu ere, egungo toponimia ofizialean lekurik ba ote duten azpimarratuz. Amaieran, bi dokumentuen transkripzioa dator.

Gako hitzak: Aralar; mendia; mugarritzea; toponimia; transkripzioa.

\section{RESUMEN}

El presente artículo recoge cuándo y cómo se realizó el amojonamiento total de la Sierra de Aralar, en base a dos documentos del archivo municipal de Etxarri Aranatz: el primero de 1523, que relata el amojonamiento de la parte que da a Gipuzkoa (un tercio del total); y el segundo, de 1857, correspondiente a la parte de Navarra (dos tercios restantes). También se recogen los aspectos referentes a los amojonamientos (condiciones, materiales, descripción, participantes), así como el análisis de los topónimos que aparecen en ambos documentos, comprobando si aún se mantienen en la toponimia oficial. Al final del artículo, se ha realizado la transcripción de los documentos mencionados.

Palabras clave: Aralar; sierra; amojonamiento; toponimia; transcripción.

\section{ABSTRACT}

The article collects when and how was carried out the total marking of Sierra de Aralar. It is based on two documents from the municipal archive of Etxarri Aranatz. The first one, dating from 1523 reports the marking of the area that borders Gipuzkoa (one third of the total area) and the second one, dating from 1857, corresponds to the area that borders Navarra (two thirds of the total area). It also includes aspects related to the marking (conditions, materials, description, participants) as well as the analysis of the toponymy that appears in both documents, checking whether the official toponymy is maintained. At the end of the article the mentioned documents are transcribed.

Keywords: Aralar; mountain; marking; toponymy; transcription. 
1. Sarrera: lanaren helburua. 2. Mugarritzea: Definizioa eta beharra. 3. Mugarriak: baldintZaK eta Deskribapena. 4. Parte-HartZaileak: herriORDEZKARIAK, ADITUAK, ESKRIBAUAK. 5. MUGARRITZEEN IKUSKATZEEN MAIZTASUNA ETA ARRAZOIAK. 6. ARALARKO EREMUAREN MUGARRITZEA. 6.1. Arañaz elkarteak eta Valmedianoko markesak 1561etik 1564ra bitartean egindako mugarritzea (finean 1523koa gogoratuz). 6.2. 1857ko mugarritzea (Arañatz - Lakuntza - Arruazu - Uharte Arakil - (Baraibar) - Errazkin - Betelu - Intza eta Gaintza Aralarrekin mugan). 7. ARALAR MENDIA 1561ETIK 1564RA BITARTEKO ETA 1857KO MUGARRITZEEN ARABERA MUGATURIK. 8. ERREFERENTZIAK. 8.1. Bibliografia. 8.2. Etxarri Aranazko artxiboko erreferentziak. 8.3. Erreferentzia elektronikoak. 9. ERANSKINAK.

\section{SARRERA: LANAREN HELBURUA}

Lan honen bitartez, Aralar mendiarekin muga egiten duten herrien eremuak nola mugarritu zituzten ikusteaz gain, erakutsi nahi dut zer-nolako garrantzia zuen herri edo herri-elkarte batentzat bere eremuko herri-lurren zaintzak, lur horiek (baso, soro zein larre) ematen baitzioten bertako biztanlegoaren gehiengoari bizirauteko aukera. Biziraun aditza erabili dut, horixe egiten zutelako mugarriztatzeen garaietako herritar gehienek, edozeren jabe izanik eta jabetza horri etekina aterata ere ezin baitzioten muzin egin modu bateko edo besteko zerga ordaindu beharrari (hamarrenak, hastapenak...).

Ez da harritzekoa, orduan, herri edo herri-elkarteek beren eremua zaindu eta kontrolatu nahi izana, eta, hala ere, maiz berrikusi behar izaten zuten hura. Eremu bateko ganadua aldamenekoarenean sartu zela; haritz eder bati ondoa jo eta eraman egin zutela; egurra; urak; belarrak; ezkurrak... Udaletxeetako artxiboetan ugari dira dokumentu zaharrak, zeintzuetan oraintxe aipaturiko egintzek sortutako salaketa eta epaiak jasotzen diren. Eta horrelakoak gertatzean agintariek erabaki zuzenak hartzeko, ezinbestekoa zen eremuen mugak erabat zehazturik eta begien bistan ezarririk izatea.

\section{MUGARRITZEA: DEFINIZIOA ETA BEHARRA}

Muga zehaztu eta hura guztia begien bistan zalantzarik gabe ezartzea zen, hain zuzen ere, mugarriztatzearen eginkizuna. 
Mugarriztatu edo mugarritu. Honela definitu du Euskaltzaindiaren hiztegiak mugarritu aditzaren ekintza: " $d u$ ad. Mugarrien bidez mugatu edo seinalatu».

Gehiago zehazten du www.enciclopedia-juridica.com web-orriak:

Amojonamiento. El acto de señalar con mojones los términos o límites de alguna heredad o tribu. El amojonamiento puede comprender tres operaciones que son: el deslinde, o fijación de las pertenencias legítimas de cada una de las heredades contiguas, mediante el examen de los títulos de propiedad y demás pruebas aducidas por los interesados; el apeo operación material de medir las tierras ya deslindadas; y el amojonamiento, propiamente dicho, la colocación de señales ya definidas.

Hiru eginkizunez osatua egon daitekeela esaten digu, orduan, mugarriztatzea: mugaketa, edo ondoko lur bakoitzaren legezko ondasunak finkatzea jabetza-tituluen bidez; mugatutako lurrak neurtzeko eginkizun materiala; eta, ezinbestean, zehaztutako mugarriak erabakitako tokietan ezartzea.

Emilio Benitez Aguado ${ }^{1}$ ingeniariak (2007, 91. or.) honela definitu zuen mugaketa:

Se entiende por deslinde al acto formal de distinguir los límites de una propiedad. (El deslinde no indica quién es el propietario de la propiedad, sí su forma y dimensiones). El amojonamiento sirve para plasmar físicamente los límites de la propiedad. La acción de amojonar es una operación posterior y consecuencia del deslinde.

Eginkizun garrantzitsua zen, bistan da, mugarriztatzearena, eta garrantzi horren lekuko nabarmena da XVI. mendean Sakanako eskualdean egindakoa Arbizu herriaren eremua finkatzeko. Arazoak izan zituzten arbizuarrek aldameneko etxarriar eta ergoiendarrekin, mende horretako berrogeiko hamarkadaren hasieran, haien ustez eurenak ziren belarrak jatera sartu zutelako Arañaz elkarteko agintariekin hitzarturik Erriberako abeltzain baten ardi saldoa.

Arbizuarrek ardiren bat hil eta artzainari kapusaia kendu ziotelako sortu zen auzia, eta, lau urteren buruan, 1537an, etorri zen epaia, zeinen arabera, 24 mugarri ezarriz herriaren inguruan, finkaturik geratu zen Arbizuren lur-eremu propioa (Erdozia, 2017a).

\section{MUGARRIAK: BALDINTZAK ETA DESKRIBAPENA}

Ohiko eginkizuna izan da mendeetan zehar, gurean gutxienez, mugarriztatzearena, eta horrexegatik dago, hain zuzen ere, nolabait arautua ere bai.

1 Valentziako Unibertsitate Politeknikoko Ingeniaritza Kartografikoko Saileko irakasle eta Valentziako Katastroko Eskualde Gerentziako Normalizazio Ataleko burua. 
Lehentxeago aipatu dudan Emilio Benítez Aguado ingeniariak honako baldintza hauek aipatzen ditu, bestalde, mugarriak behar bezala ezartzeko:

Requisitos del amojonamiento: - Materiales; piedra natural o de hormigón. • Forma (se quiere estabilidad). Troncocónica o piramidal, grande y pesada. • Debajo de las piedras se colocará una capa de carbón, cal o ceniza que sirva de testigo en el caso de desaparecer el mojón. Se colocarán tantos hitos como vértices tenga el perímetro de la propiedad. Cuando no se pueda colocar un mojón, se pondrán cerca mojones que definan dos líneas cuya intersección se halle en el punto a amojonar.

Eta Valentziako Unibertsitateko irakasleak aipatzen dituen baldintzak XVIII. mendean gurean nola betetzen ziren erakusten digu Etxarri Aranazko Udal artxiboko 1777ko dokumentu batek:

[...] puso en su lugar abriendo la fosa o augero otro nuevo mojon de Piedra Arenisca poniendo por basa o cimiento en señal de verdadero vestigios del lexitimo mojon, pedazos de texa, carbón, y cascaras de huevos y introdujo dentro en pie y medio en quadro y de altura lo metido en tierra dos pies y medio menos una onza teniendo dicho mojon de altura desde la superficie tres pies y siete onzas, labrado, triangularmente de modo que el uno de los lados del dicho triangulo mira a los montes y términos de la Comunidad de Arañaz [...].

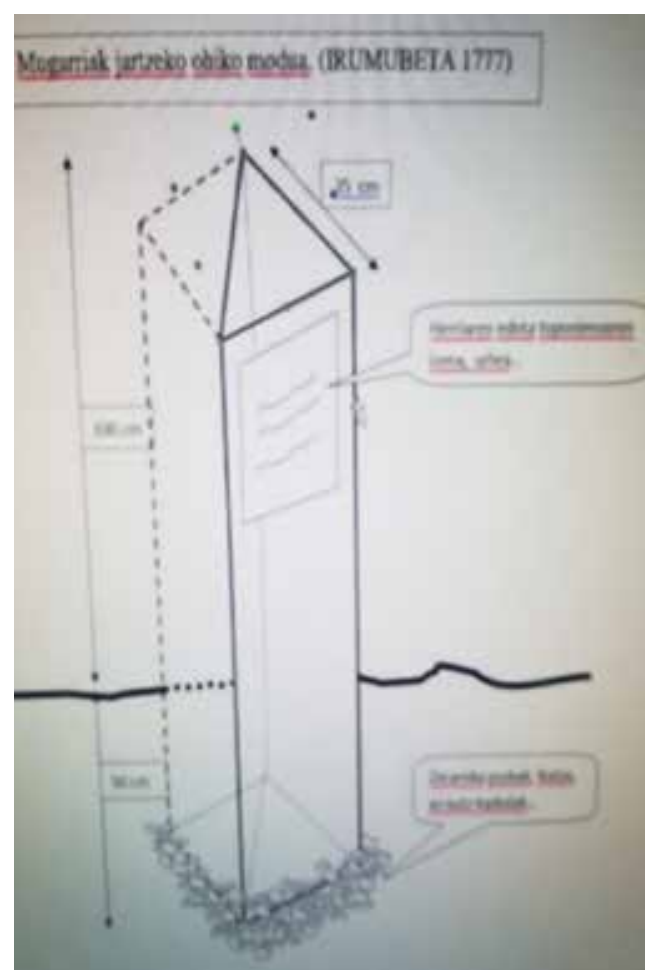

1. irudia. 1777 ko mugarria dokumentuaren arabera.

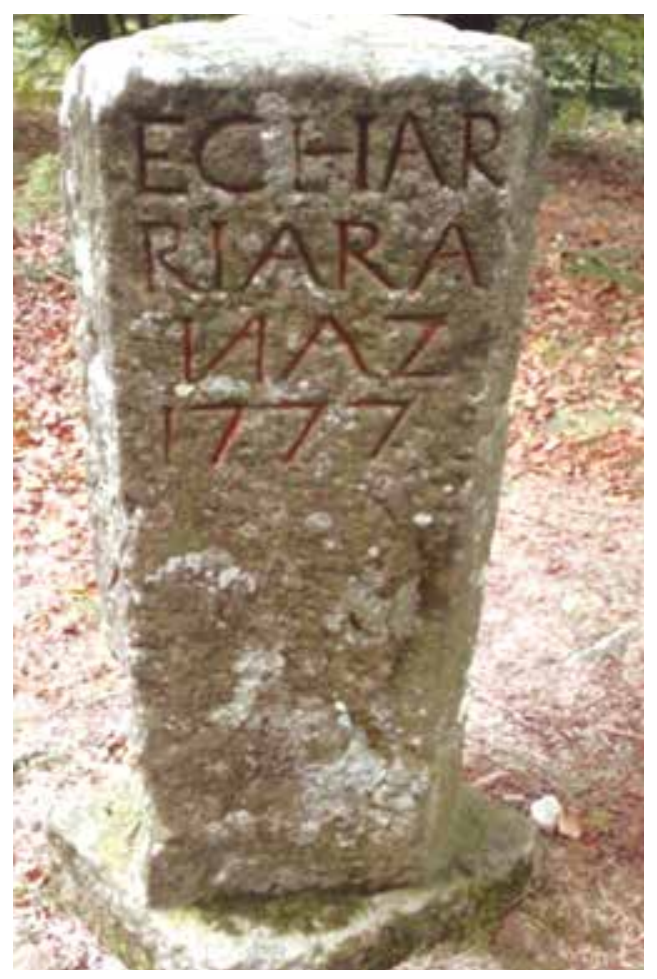

2. irudia. 1777ko mugarria. 
Etxarri Aranazko ipar-mendebaldeko mugan Irumugeta toponimoaren eremuan dagoen mugarria nola jarri zuten deskribatzen digu dokumentuko zati horrek. Mugarriak hiru muga adierazten ditu: Arañazko elkartea (Etxarri Aranazko basoa), Burunda (Bakaikuko basoa) eta Valmedianoko markesarena (Ataungo basoa).

Aurreko irudietan ikus dezakegu Irumugetako mugarria: ezkerrekoan, nik neuk dokumentuko deskribapenari jarraituz marraztutakoa; eta, eskubikoan, mugarriaren argazki bat bere kokalekuan.

Bestalde, 1889an, Etxarri Aranatzek eta Bakaikuk (desagertuak ziren ordurako Arañaz elkartea eta Burundakoa) bi herrien arteko muga markatzeko hirurogei mugarri paratzeko baldintzak ezarri zituzten, eginkizun hori enkantean esleitzeko ondoren. Baldintzak eta baita mugarri berezi baten marrazkia ere utzi zizkiguten Etxarri Aranazko Udal Artxiboko dokumentuan.

Lehen-lehenik, mugarrien neurriak aipatu zituzten: $0,80 \mathrm{~m}$ luze agerian eta 0,50 estalirik, eta oinarria karratua, 0,30 m-ko aldeekin eta 0,09 $\mathrm{m}^{2}$-ko azalerarekin.

Enkantean lana hartzen zuenak, hau da, esleipendunak, honakoa egin behako zuen: mugarriak sortu, landu eta aldez aurretik erabakitako toki zehatzetara garraiatu.

Mugarriak sortzeko lekuak ere esleipendunak erabaki beharko zituen, betiere eremu pribatuetan ez egiteko baldintzapean, ondoren balizko erreklamazioak ekiditeko.

Lehentxeago nioen bezala, mugarri berezi bat ere egin beharko zuen esleipendunak, oinarri triangeluarra izanen zuena, metro bat agerian utzita eta $0,50 \mathrm{~m}$ lur azpian. Oinarriko triangelua ekilateroa izanen zen, alde bakoitza $0,35 \mathrm{~m}$-koa izanik. Irudia ere erantsi zuten dokumentuan:

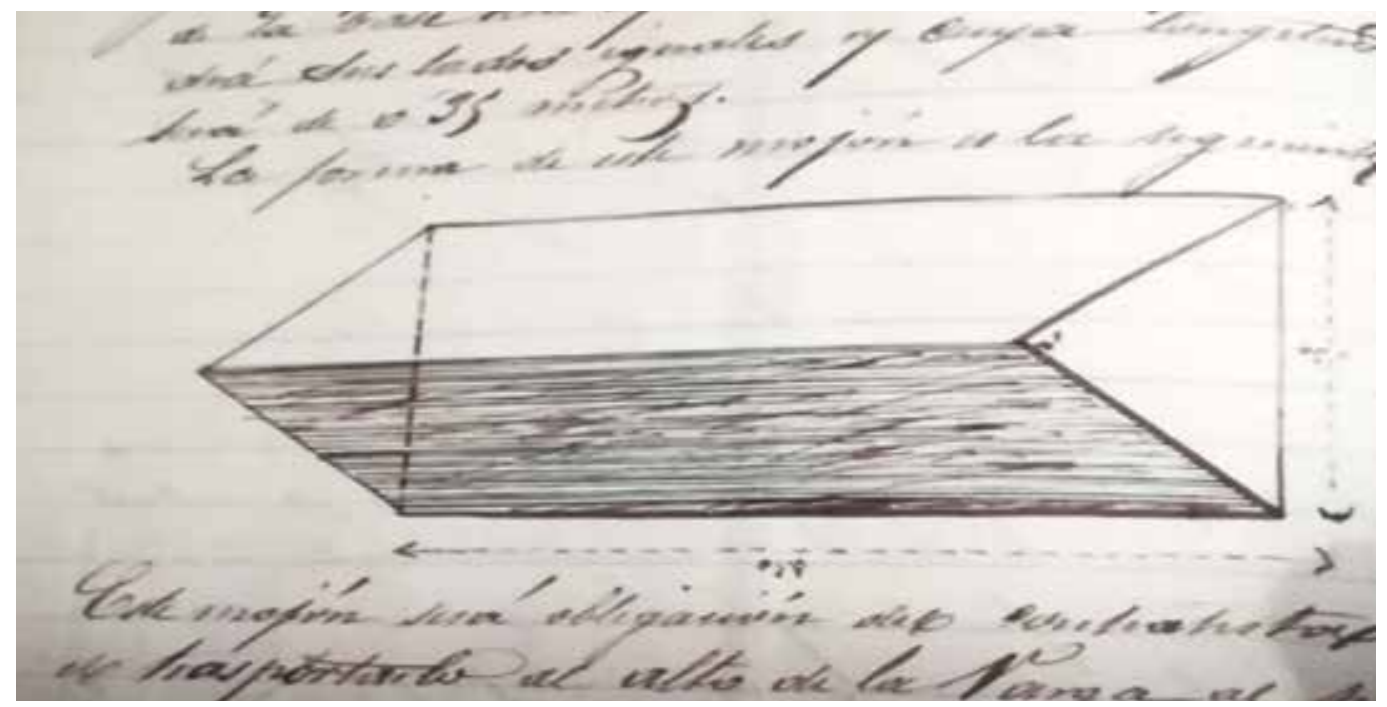

3. irudia. 1889 ko dokumentuko marrazkia. 
Mugarri hori Barga gainera eraman beharko zuen esleipendunak, eta mugarri guztiak paratzeko epea ere ezarri zioten.

Ordainketa nola eginen zen ere aurretik erabaki zuten: haiek ezarritakoan ordainduko zioten hogei mugarriri zegokion kopurua, ingeniariak oniritzia eman ondoren. Eta hasi, Irumugetatik (Etxarri Aranatz, Burunda eta Ataun) hasiko zen mugarriak jartzen.

Esleipenerako baldintzetan, mugarri bakoitzeko zazpi pezeta eta erdi ordainduko zirela esaten zen, baina, enkantea burutu zenerako, 12,5 zentimoko jaitsiera ${ }^{2}$ izan zuen mugarriaren salneurriak, eta, horregatik, 7,35 pezeta ordaindu ziren azkenean mugarri bakoitzeko. Lanaren ardura hartu zuena, hargina, Bernardo Ynchorrondo etxarriarra izan zen.

\section{PARTE-HARTZAILEAK: HERRI-ORDEZKARIAK, ADITUAK, ESKRIBAUAK}

Mugarritzeetan, normalean, mugarritu behar zen eremuko partaide ziren herrietako ordezkariak izaten ziren. Gehienetan alkatea eta zinegotziren bat edo beste («rexidor»), alde batetik, betiere eremua eta herriko lurrak ongi ezagutzen zituztenak; eta eskribau ofizial bat, bestetik, hartutako erabakiak dokumentu batean islatu eta jasotzeko.

Hona jarraian 1699ko lastailaren 11ko mugarriztatzeetan Arañaz elkartean eginkizun horietan aritutako arduradunak («Autos de amojonamiento de los Monte de Arizalco, Bargas, Berain, y Sel de Uzuar»).

Parte-hartzaileak edo mugarritzeetako protagonistak:

- Eskribaua: «Pedro de Jauregui».

- Etxarri Aranatz: «Miguel de Artieda, Atte (alkate) y juez ordinario; Miguel de Miguel de Echarri, vecino y diputado ${ }^{3}$; Fermin de Aguirre, almirante; Juan Bruno de Bacaicoa, regidor; Domingo de Bacaicoa menor, vecino y diputado: Esteban de Maiza, regidor; Miguel de Maiza, regidor».

- Ergoiena: «Juanes de Aldaburu, Atte ordinario del valle de Ergoiena; Martin de Urquizu, Rex ${ }^{\text {or }}$ del lugar de Lizarraga; Pedro Martines de Larraza, vecino y diputado de Lizarraga; Martin de Peruzurguin, vecino y diputado de Lizarraga; Jose

2 Esleipendunak, hasieran, baldintzetako salneurrian hartu zuen enkantea, baina, ondoren, beste batek hartu zuen baldintzetan aurrikusitako jaitsierarekin, hots, mugarri bakoitzeko 6,25 zentimoko jaitsierarekin, eta, atzera berriz, esleipendunak beste hainbeste jaitsi behar izan zuen lana egin ahal izateko.

3 Horretarako «aukeratua», "aditua». 
de Ascundia ${ }^{4}$, diputado de Lizarraga; Juanes de Aldaia, rexidor del lugar de Torrano; Christobal de Lizarraga, diputado de Torrano; Juanes de Aguirre, diputado de Torrano; Jose de Mozos, regidor del de Unanua; Martin de Mendibe, diputado de Unanua».

- Arbizu: «Garcia de Arbizu, alias Vicario, vecino y diputado; Juanes de Leiza, vecino y diputado».

\section{MUGARRITZEEN IKUSKATZEEN MAIZTASUNA ETA ARRAZOIAK}

Mugarritzeak, ohikoak, hainbat urtetik behin ${ }^{5}$ egiten ziren (oraintxe aipaturikoa, esate baterako), aurretik aztertutako dokumentuak kontuan izanik eta mugek zehaztutako moduan jarraitzen zutela ziurtatzeko. 1571n egindako ikuskatzean Etxarri Aranatzeko eta Valmedianoko markesak lekuko gisa eramandako Juan de Gorricho apezaren hitzetan, berrogeita hamar urtean zehar makina bat aldiz ikuskatu zituen berak eremu horretako mugarriak, eta, kasu honetan beste behin, honela dio une horretako auziaren harira («pleito»):

Testigo el d(ic)ho Dn Juan Gorricho clérigo beneficiado de la Parr(ochi)al Yglesia de Sta Maria de la Villa de Echarri Aranaz e vecino de ella testigo present(a)do por el d(ic)ho Ju(e)z Arza en el d(ic)ho nombre de los d(ic)ho sus p(ar)tes para el d(ic)ho pleito que a e trata con las Universidades de Amezqueta Abalcisqueta e sus consortes habiendo jurado en forma dijo e depuso lo sig(uien)te =

A la prim(er)a preg(un)ta ${ }^{6}$ dijo que conoce a mu(cho)s vecinos de las universidades de Ataun Amezqueta e Abalcisqueta por vista e abla e conversaz(io)n y con ellos e con cada uno de ellos ha tenido e tiene e por la misma conoce al d(ic)ho Dn Phelipe de Lazcano e sabe e tiene noticia del termino d(ic)ho e nombrado Agaunza e del termino que se dice Alleco sobre que es este pleito por haver estado en ellos y en cada uno de ellos por m(ucha)s e diversas e cinquenta años poco mas o menos de esta parte =

Respondiendo ${ }^{7}$ a las preguntas g(ene)ra(le)s de la ley dijo ser de hedad de sesenta y cinco años poco mas o menos e que no es pariente de ninguna de las $\mathrm{p}$ (ar)tes ni le va interés en este pleito ni concurren en el ninguna de las caudades que la ley dispone y su deseo es balga la jus(tici)a a la p(ar)te que la tiene =

4 Axkondo, seguru asko.

5 Rafael Carasatorreren documentanavarra.blogspot.com helbide elektronikoan jasota dagoen 1854ko mugarritzean (Arañaz elkartea eta Valmedianoko markesa) honela dio: «...con el objeto de que la citada mojonera se conserve con toda claridad que desean, determinan que de seis en seis años se haga un reconocimiento de la misma fecha y testigos los mismos».

6 Ezkerreko aldean: «1." ".

7 Ezkerreko aldean: «2."». 
A la tercera ${ }^{8}$ preg(un)ta dijo siéndole leído e mostrado el memorial de los hitos y mojones y señales de que la pregunta hace mención dijo que sabe e tiene noticia de todos los d(ic)hos mojones hitos y señales y linderos contenidos en el d(ic)ho memorial por los haver visto andado y apeado por m(uch)as veces los d(ic)hos mojones en el t(iem)po de los d(ic)hos cinq(uen)ta años e por tales mojones e linderos del d(ic)ho term(ino) de Agaunza y Alleco e por tales los ha tenido e tiene este tes(tig)o en su tiempo e por endreceras e partidas comprensas dentro del d(ic)ho termino e nombre general de Agaunza lo qual sabe porque este testigo en todo su tiempo a sido muy aficionado a cazar de todo genero y demandas de azores que hay en los d(ic)hos términos e por muchas veces en cada un año de los d(ic)hos de suso ha ido y estado y reconocido el d(ic)ho term(in)o de Agaunza y los d(ic)hos mojones e linderos de el que son los declarados en el d(ic)ho memorial que son los sig(uien)tes $=$

Horrela erakusten du, era berean, 1852an Arañaz elkartearen eta Uharte Arakilen artean egindako mugarritzeak, zeinaren hasieran adierazten duen, datu aipagarri moduan, ez zutela aspaldian (138 urte) mugarritzea ikuskatu:

En el monte denominado de Ondaz mojonera de la Villa de Huarte-Araquil y Comunidad denominada de Arañaz a diez y seis de setiembre de mil ochocientos cinquenta y dos. Estando juntos y congregados como lo tienen de costumbre los señores [...] que desde la cabecera del termino de debate hasta encontrarse con la peña que en lo antiguo se denominaba Gazteluco barga no se ha verificado ningun reconocimiento de mojones desde diez y siete de junio de mil setecientos y catorce, por cuyo motivo [...] antes de que por esta razon se susciten algunas diferencias entre ambas comunidades.

Baina, gehienetan, zenbait arazo edo salaketa zirela medio suertatzen zen eremu jakin bateko mugarritzea aztertu beharra hala egiteko data iritsi baino lehen. Azken horien kasuan, normalean bi eremu mugakide nagusiren artekoak izaten ziren mugarri-ikuskatze berriak, baina, zenbait kasutan, eremu jakin bateko partaide ziren herrien artekoak ere izaten ziren. Horietako bat dugu, esate baterako, 1804. eta 1805. urteetakoa, Etxarri Aranatzen eta Ergoienaren artekoa, 1543ko eta 1559 ko epaietan oinarritua («sentencias arbitrarias»). Auziko bi aldeak Arañaz elkarteko kide ziren, eta haien artean suertatu zen liskarra, Ergoienak etxarriar baten txerriak atxilo hartu zituelako (edo etxarriarren baimenarekin gutxienik, ustez lizarragatarren eremuan sartzeagatik). Arañaz elkartea Etxarri Aranatz, Arbizu eta Ergoiena herriek osatzen zuten, eta, dokumentuak erakusten duen moduan, argi eta garbi ezarririk zeuzkan erakundeak bere arau eta ardurak.

Ikusi honako testu honetan nola zehazten den ganadua atxilo hartu edo zigorrak ezartzeko ardura:

8 Ezkerreko aldean: «3. ${ }^{\mathrm{a}} »$. 
Y porque la capitula $6^{a}$ de la sentencia arbitraria del año de 1559, folio 27 , no autoriza al valle [Ergoienari buruz ari da], su alcalde, rexidores, ni costieros ${ }^{9}$ para que puedan carnerear ${ }^{10}$ ganado alguno de cerda, sino que el alcalde del valle con sus jurados, y comunicacion de los que le pareciere, puede acordar hacerlo de las reses menores, enviando dentro de medio dia su quarta parte a los de la villa; y la facultad de carnerear cerdos unicamente esta concedida al alcalde y rexidores de la villa [Etxarri Aranazkoez ari da] y al alcalde de montes de la comunidad de Arañaz (en que son comprensos la villa y valle) que siempre ha sido, es y debe ser uno de los vecinos de la villa, y a el qual estan sujetos los costieros de montes de ella y del valle; y aunque los de este quando particularmente salen a reconocer y custodiar las endreceras situadas desde el Rio Mayor hacia Estella pueden prendar cualesquiera ganados granados y menudos y tambien a los que cortaren fusta materia y leña con obligacion de preservar al alcalde del valle y este puede devolver bajo fianzas lo prendado, o carnerear las reses menores en la forma referida, no se estienden esas facultades a poder carnerear cerdos como le consta muy bien al valle.

Liskarra edo arazoa 1804. eta 1805. urteetakoa da, baina, lehentxeago esan dudan moduan, horixe argitzeko arauetara jo zuten, eta arau horiek 1559koak ziren. Horien arabera, soilik Etxarri Aranazko alkateari eta zinegotziei zegokien ardura hori, ganadu larriekin behintzat, edo, bestela, Arañaz elkarteko ahaltzain edo basozainari («alcalde de montes»), eta hori ere, ezinbestean, etxarriarra izan behar zen. Eta gainerako basozainak haren agintepean zeuden, bai Etxarri Aranazkoak, bai Ergoienakoak.

Bestela ere, badugu adibide argia bi eremu nagusiren arteko liskar edo auzi bati dagokionez gurean, Etxarri Aranazko udal artxiboan dagoen 1739ko dokumentu batek erakusten digun moduan. Kasu horretan, hauek ditugu auziko aldeak: Arañaz elkartea, batetik, eta Lakuntza eta Uharte Arakil herriak, bestetik. Beriain mendiaren azpian, aipatu eremuen arteko mugan bertan apika, unanuar batek haritz bati ondoa jo zion, baina, behin botata, lakuntzarrek eraman zuten haritza, beren eremuan zegoela argudiatuz.

Dijeron que en dho monte de Arranaz habido y hay sus mojones que dibiden parten y señalan lo que es sitio y paraje de la comunidad y valle de Arañaz y lo que es termino y monte facero y comun de dhas villas de Huarte y Lacunza y con el motivo de haber cortado y derribado un roble cierto particular de dho lugar de Unanoa y llevado aquel los vecinos de dha villa de Lacunza sin embargo de haberlos prendado el costiero de montes de dha villa de Arvizu para saber si el prendamiento fue legitimo por la duda del paraje en que se hizo el corte, dado parte a dhos pueblos y de conformidad prefilado el dia de oy se han juntado todos los otorgantes y enterados del sitio y de personas que en dho monte han andado con sus ganados pastoreando y que faltan

9 Basozain.

10 Atxilo hartu. 
algunos mojones a fin de evitar para en adelante qualquiera duda y confusion en la parte inferior de dho monte que es donde se derribo el referido roble.

Bistan da, orduan, zein eta zeinen artekoa izan zen 1739ko auzia, baina mugarritze hori aztertutakoan izanen ditugu argibide gehiago, oraingoan Aralarko mugarritzearekin baikabiltza eta honexek ez baitio horri eragiten.

\section{ARALARKO EREMUAREN MUGARRITZEA}

Mugarritzeak zertarako eta nola egiten ziren argitzen saiatu ondoren, jarraian, Euskal Herriaren erdigunean dagoen Aralar mendiarena aztertuko dut, hiru mendeko aldea duten bi dokumentuz baliaturik.

Bi dokumentuak Etxarri Aranazko udaletxeko artxiboan daude, eta horietan erabat mugaturik ageri zaigu Aralar mendiaren eremu osoa, edo ia osoa, zeren bigarrenean ezin izan baitzuten Larraun haraneko Baraibar herriari zegokion eremua bistaratu, herri horretako ordezkariak ikuskatze hartara ez ziren agertu eta.

Lehen mugarritzearen dokumentua 1561etik 1564ra bitartekoa da, nahiz eta, testuak berak dioen moduan, 1523koa izan funtsean. Bertan, Gipuzkoa aldera ematen duen eremua dago mugarriturik. 16 mugarri aipatzen dira dokumentu horretan.

Bigarrena 1857koa da, eta, aurrekoan amaiera markatzen duen mugarrian hasita, Aranatz, Arakil, Larraun eta Araizko eremuak mugarritu zituen. Guztira 73 mugarri aipatzen ditu, baina kontuan izan behar da Baraibarkoak falta direla.

\subsection{Arañaz elkarteak eta Valmedianoko markesak 1561etik 1564ra bitartean egindako mugarritzea (finean 1523 koa gogoratuz)}

Dokumentua: (Legajo num. 9. Año de 1561 al 1564. «Comprende los autos de Amojonamiento desde Soilas bizcar hasta Oregui gaña entre el Sr. Marques de Valmediano y los pueblos de Amezqueta y Abalcizquieta».) (4.1.1. caja 2, Etxarri Aranazko Udal artxiboa).

Dokumentuaren izenburuak dioen moduan, XVI. mendearen erdialdekoa dugu hauxe, baina, funtsean, lau hamarkada lehenagoko mugarriztatzea gogoratzen du bertan, 1523koa. Guztira hamasei mugarri aipatzen dira dokumentuan, Gipuzkoaren eta Araizko haranaren arteko mugan hasita, mendebaldera joaz. Honako hauek dira, laburbildurik, bertan aipatzen direnak, non dauden kokatuak ere adierazirik:

1. Soilas bizcar. Aralarko iparralde betean, Gipuzkoaren eta Araitz Haranaren mugan. Hemen Irumugarrieta toponimo esanguratsua dago. Toponimo horren osagaiak, seguru asko, soil $+-a+-z u$ eta bizkar izanen genituzke. Lehen osagaiak landaretzarik gabeko eremua adieraziko luke, beste biak morfemak ditugu, eta azkenak lur gorunea esan nahiko luke, gaztelaniazko «loma». 
2. Arrate de Gorostiaga (entre los dos Cerros de Soilas [...]). Aurrekotik hego-mendebaldera, Aralarren eta Gipuzkoaren arteko muga jarraituz. Arrate, harri arteko pasa, gaztelaniazko "desfiladero» adierazteko erabili da euskal toponimian, eta gorosti fitonimoak, -aga morfemarekin, gorostien lekua adierazten du. Eta eremu zabala izanik, zazpi mugarri jarri zituzten bertan iparraldetik hego-mendebaldeko norabidean muga zehaztuz.

3. Soylas vizcarbarrena. Aralarko planoan, Arrataza de Soilaz Bizkarbarrena, aurrekoaren ondoan. Lehen mugarriaren eremuaren barnealdean (barrena).

4. Cerro de Gorostiaga. "Uniones de Amezqueta y Villafranca» eremuekin muga eginez. Bigarren mugarria harratean edo pasalekuan, eta hori, aldiz, eremu bereko muinoan.

5. Gorostiaga arreguia. (H)arri eta (b)egi +- a dira bigarren hitzaren osagaiak, hau da, leku irekia.

6. Gorostiaga zavala (Llano de Gorostiagazavala). Aurreko mugarrien kokalekuaren zabalgunea.

7-8. Gorostiagagaña (un mojon en Gorostiagagaña... pusimos otro nuevo...). Eremuko tokirik altuena (gaña).

9. Tricuarri. (Cerro de Tricuarri... Suzon de Elordielusa... Peña Verga...). Dolmena adierazten du: La Piedra de Tricuarria. Suzon ${ }^{11}$ landare mota bat da gaztelaniaz; beraz landare horren eremua adieraziko luke toponimoaren lehen osagaiak. Bigarren osagaia konposatua da, eta elorri $+-d i+e l u(t) s$ dira bere osagaiak: elorrien tokia, baina eguzkiak gutxi ematen duena, ospela edo laiotza, horixe baita azken osagaiaren esanahia: barga seguru asko, amildegia.

10. Errenaga (Errenaga y del Cerro de Tricuarria hasta la Piedra de Tricuarria...). Aralarko toponimian, horrela, baina era sinkopatuan erabiltzen da: Ernaga. Erren edo arantza askoko lekua.

\section{Pozo grande de Errenaga.}

12. Buztizategaña (Buztizategaña... Punta del Pozo... Errenagachiquia... Errenagachipia). Aralarko toponimian Buztirateko ateka eta Buztirategañeko bidea, baita cerro de Buztirate (1561) eta Bustirategaña ere (1846). Lehenaren iruzkinean honako hau diote NTM XIIn: «Ormazarretatik Ernagaa ateratzen den halako ate... Holaxe, zea bat

11 Honela dakar RAEk: «suzón Del lat. senecio, -ōnis. 1. m. zuzón»; baita honela ere: «zuzón De suzón. 1. m. hierba cana». Senecio vulgaris da landarea: «suzón s. m. BOTÁNICA Zuzón, planta compuesta, de tallo ramoso, hojas gruesas y partidas y flores amarillas tubulares» (Gran Diccionario de la Lengua Española, 2016, Larousse Editorial, S.L.). 
da, tunel bat pasako balitz bezala». Ate eta gain + -a soilik eman ditzakegu toponimo horietan osagai segurutako. Bestalde, aipagarria da txiki eta ttipi bi moduetara erabili izana parentesi arteko azken toponimoa.

13. Ormazarreta (Cerro de Buztizate... Hacia Ormazarreta). Aralarko toponimian honela dakar: «En este importante raso está situada una gran majada, que es compartida por varios pastores, a diferencia de la mayoría de las majadas del Aralar navarro, que suelen ser indviduales. Cerca de este paraje, en las laderas de Aparain, estásituada la sima de Ormazarreta, que con sus 375 metros de profundidad es la mas importante de Aralar». Mendebaldera joaz, Aranazko herrietako eremuetatik hurbil. (H)orma + $z a(h) a r+$-eta dira bere osagaiak.

14. Urrestarazu barrena (Cerro grande de Buztizategaña...). NTM XII historikoan Urrestarazu barrena ageri da, hizpide dugun dokumentuari erreferentzia eginez. Ez da bestela Aralarko gaur egungo toponimian ageri. Hurritz fitonimoa du oinarrian.

15. Leceta Arañavea o Aqueaz (la Punta de Aqueaz...). Lehen biak NTM XII historikoan soilik ageri dira horrela, eta hirugarrena Aqueaiz gisara ere historiko berean, baita, 1846an, Aqueiz moduan ere. Leizeen eremua, lehenaren kasuan; eta, bigarrenean, (ih)ara + (ga)in $+-a>$ araña seguru asko lehen osagaiaren oinarrian, eta be(be) $a$ amaieran. Honela azaldu nuen Euskera aldizkarian (Erdozia, 2017b) argitaratutako artikuluan azken bilakabide hori: "Araña $<$ "araañ $a<$ "yaraañ $<$ "yaragaña $<$ ihara + gain $+-a[\ldots] »$.

Mikel Belaskok (2000, 61-62. or. ) Arain (Bidankoz) eta Arainburu (Goizueta, Zubieta) toponimoei buruz honela esan zuen: «Probablemente de arain (variante de haran 'valle, vaguada') aunque por tratarse de un alto no debe descartarse que la terminación sea una contracción de gain 'alto'».

16. Oreguigaña (...a Oreguigaña donde pusimos otro mojon desde alli hasta confinar con el Mojon de Echarri por las cumbres Aguas vertientes). Etxarri Aranazko toponimian Odoigeñe eta Oroigeñe.

(7. puntuko mapan ikus daiteke 16 mugarri horien balizko kokapena).

\subsection{7ko mugarritzea (Arañatz - Lakuntza - Arruazu - Uharte Arakil - (Baraibar) - Errazkin - Betelu - Intza eta Gaintza Aralarrekin mugan)}

Oregigaña mendian elkartu ziren Arañaz elkarteko, Lakuntzako, Arruazuko, Uharte Arakilgo, Errazkingo, Beteluko, Intzako eta Gaintzako ordezkariak, 1686ko mugarritzea oinarri harturik, herri bakoitzak Aralarko eremuarekiko mugak berrikusteko.

\subsubsection{Parte-hartzaileak}

Eskribaua: Martin Francisco Saralegui.

Kontsultorea: Baso Alvarez de Carballo. 
Arañaz elkartea.

Etxarri Aranatz: Martin Artieda, alkate, Jose Erdocia eta Miguel Jose Huici, erregidoreak.

Ergoiena: Matias Lizarraga, Ergoienako alkate; Martin Yjurco, Lizarragako erregidore.

Arbizu: Jose Martin Iriarte, alkate.

Lakuntza: Isidro Garciandia, alkate.

Arruazu: Gabriel Cristobalena, alkate.

Uharte Arakil: Miguel Francisco Irañeta, alkate; Jose Vicente Fernandino, erregidore; Domingo Razquin, Leon Gorriti, adituak.

Irañeta, Ihabar, Hiriberri: Ignacio Cia.

Araitz Harana, Errazkin, Betelu: D. Francisco Yeregui, Martin Vicente Otermin eta Martin Jose Martinicorena, eremu horietako ordezkari moduan.

Lan honetako lehen mugarritzekoaren jarraipena izanen genuke hauxe (1523koarena, funtsean). Gogoratu hura, 6.1 puntua, Oregigañan utzi dugula, Soilas bizkar toponimotik hasitako mugarritzean, datu haiekin eta hauekin egin dudan Aralarko mapan geroxeago ikus daitekeen moduan.

Jarraian, Putterri ondoan dagoen Oregigaña (Oroigeñe etxarriarrendako) toponimotik hasi eta, egungo Ergoienako eta Arbizuko ipar-ekialdeko mugetan barna, Lakuntzak eta Arruazuk Aralarrekin muga egiten duten eremuetako zenbait mugarriri izena ematen dieten leku-izenak aztertuko ditut, mendebaletik hego-ekialderako norabidean:

(1-2) Oreguicobalsa. Etxarri Aranazko toponimian Odoigaña dago jasota eremu horretan. Hala ere, mugarritzean bezala ageri da dokumentaturik 1794an. Bigarren osagaia, begi bistakoa: ur-baltsa.

(3) Putarri, Putarricozuloandia. Etxarri Aranazko toponimian Puttarri, eta, herritarrek bokal irekia asimilaturik, Putterri. Modu ezberdinetan dokumentatua, zaharrena 1197an: Bueytarri. Osagaiak, bistan da: $p u(i) t(r) e+(b)$ arri. Bigarrena toponimian Puttarriko zulo handia ere; azken osagaiaren hasierako bokala diptongaturik: (b)aundiye.

(4-5) Gainchiquieta. Aralarko toponimian Gaintxirieta, inolako azalpenik gabe. Gain + txiki + -eta dira seguruenik osagaiak, gain txikiz osaturiko eremua adieraziz.

112 Cuadernos de Etnología y Etnografía de Navarra (CEEN), 94, 2020, 99-133 ISSN: 0590-1871 ISSN-e: 2530-5840 ISSN-L: 0590-1871 
(6) Siasbelceta. Arbizuko toponimian Siasdegiak, Siatsa, Siatseta, Siatsetako etxe txikia eta Siatsetako harri gaiztoa. Siats toponimiako generikoa da, eta toki hezea, madura, adierazten du. Beltz izenondoak ez dio, seguruenik, koloreari erreparatzen, eremuaren desegokitasunari baizik.

(7-8) Mandueta. Horrelaxe Aralarko toponimian, $1.144 \mathrm{~m}$-ko altuera duela baino ezer gehiago adierazirik. Osagaiak, seguru asko: mando + -eta.

(9) Tristansare. Hau ere honelaxe Aralarko toponiman. Tristan izeneko norbaiten sarea (saroi), hau da, ganadua gauez biltzeko tokia, eta batzuetan eraikuntza ere bai.

Elurzulota («nebera natural» mugarritzean). Etxarri Aranazko toponimian, Elurzuloeta. Mugarritzeak gaztelaniaz adierazten du toponimoaren esanahia.

(10) Lizardi. Aralarko toponimian, Lizardieta, eta, NTMn, 1209 m-ko altuera duela soilik. Lizar + -di.

(11-12) Aiceguigaña. Arbizuko toponimian, Aitzegigaña. Osagaiak (b)aitz + (b)egi + gain $+-a$ dira, haitzez osatutako hegalaren edo maldaren gaina, beraz.

(13-14) Meceriangaña. Arbizuko toponimian, Mezeriain, Mezeriain barreneta eta Mezeriaingo borda / iturria(k) / larrea / zuloa / zulo handia. Azken osagaia -gain da seguru asko, eta erredundantea gainera, Mezeriain toponimoak, agian, -(g)ain duelako azken osagai moduan.

(15) Arrartechipia. Aralarko toponimian, Arrartetxipia, eta, dokumentaturik, Arratechipia de Amuruchate, 1685ean. (h)arri + a(r)te + ttipi +-a dira bere osagaiak, bigarrena bi modutara erabilia ageri baita. Edozein modutara, mendiko pasa txikia ("portillo») adierazten du.

Erchia de Corosabarren. Arbizuko eta Aralarko toponimian, Korosabarreneko harratea. Mugarritzeko lehen osagaiak, hertsia, toki estua edo mehargunea adierazten $\mathrm{du}$, eta bigarrenaren osagaiak, seguru asko, korotz $+-a+$ barren dira, txistukarien txandaketa edo nahasketa dela medio.

(16)(1) Yrumugueta. Arbizuko azken mugarria eta Lakuntzako lehena. Uharte Arakilgo eta Aralarko toponimian ageri da, eta beste eremu askotan ere bai.

(2) Churuchuberri. Aralarko toponimian, Txuritxuberri. Etxarri Aranazko toponimian Txurituzarreta dago, eta honako hau nioen bere iruzkinean lehen osagaiari buruz: «zuhaitzik edo landarerik gabeko tokia izanen litzateke». Arañaz elkartearen mapan Churichuzarreta ageri da. Aspaldikoa da Etxarri Aranazkoa, orduan; berriagoa Aralarkoa.

(3) Beraingoarria. Lakuntzako eta Aralarko toponimian, Berigaingo harria. Osagaiak, seguru asko: ber $(a)+-(g)$ ain $+-g o+(b)$ arri $+-a$. Aurrez aurre du Beriain mendia haranaren hegoaldean. 
(4-5) Larlucegaña. Lakuntzako toponimian, Larluz, eta Aralarkoan, Larluzegaña. Osagaiak, bistan da: lar $(r e)+\operatorname{luz}(e)+-$ gain $+-a$.

(6-7) Irucilachiquita. Lakuntzako toponimian, Iruzulotxikieta. Eta osagaiak, bistan da: (b)iru + zulo + txiki + -eta. Aipagarria da mugarritzean bigarren osagaiaren /i/ erdiko bokal itxiaren erabilera, Euskal Herriaren iparraldearen eta ekialdearen antzera: zilo.

(1-2) Aubiagaña. Lakuntzako eta Arruazuko toponimian, Aubigaña, eta Arruazun, gainera, Aubia eta Aubiako sarea. Arruazuko lehen bi mugarriak.

Iruranlarrea. Ez da ageri Lakuntza, Arruazu, Uharte eta Aralarko toponimia ofizialean. Osagaiak ikusirik, pentsa daiteke hiru eremu hartzen dituen belardia adierazten duela: Lakuntza, Arruazu eta Aralar.

(3) Ervillarri. Arruazuko toponimian, Erbillerri, honako iruzkin honekin: «Los informantes lo traducen como pueblo de liebres». Irañetan erbil erabiltzen dute lur mokorrak hausteko mailu handia adierazteko. Herri, bestalde, eremua adierazteko erabiltzen da toponimian.

(4) Belaztangoentrada. Aralarko toponimian, Belaztan. Eremu horretarako sarrera da, beraz. Belatz da, seguru asko, lehen osagaia.

(5) Elormenta. Arruazuko toponimian, Elurmenta. Bere osagaiak, seguru asko, elur + benta dira, eta elur asko izaten den eremua adierazten du.

Orormendigaña. Ez da ageri inguruko herrietako toponimian, ezta Aralarko ofizialean ere.

(6) Geltilarri. Aralarko toponimian, Jentilarri eta Jentilarria, lehenak eremua eta bigarrenak trikuharria adieraziz, seguru asko.

Aragoarria. Hau ere ez da ageri inguruko toponimian. Osagaiak, akaso, (ib)ara $+-k o$ + (b)arri + -a dira, hau da, errotako harria.

(7-8) Debata. Lakuntzako, Arruazuko eta Aralarko toponimian ageri da. Aurreko mugarritzean Debate moduan ageri da eta, eremu ezberdinetako muga izanik, beti arazoak izan dira bertan («debate»). Sakanan, Aralar aldeko hau eta baita Arnatz-Ondatz eremuan ere ageri da aipatu toponimoa.

(8)(1) Debatagaña (hau ez da ageri NTMn). Arruazuko azken mugarria eta Uharte Arakilgo lehena.

(2-3-4) Debatako larrea ere ageri da mapan. San Miguel in Excelsis aipatzen da mugarrien norabidea markatuz.

114 Cuadernos de Etnología y Etnografía de Navarra (CEEN), 94, 2020, 99-133 ISSN: 0590-1871 ISSN-e: 2530-5840 ISSN-L: 0590-1871 
(5) Araizarrate. Soilik 1857ko dokumentuan eta horrela jaso zuten NTMn ere. Osagaiak, agian, (ih)ara + (h/g)aitz + (b)arr(i) + ate, Euskera aldizkarian (Erdozia,2017b) iradokitako bidetik (ikus 6.1 puntuko 15. mugarriaren azalpena).

(6-7-8-9-10-11-12) Ecelzieta. Ecelzietagaña 1857ko mugarritzean soilik ageri da, baina Ezezeta, Ezezetako iturria, Ezezetako iturtxar eta Ezezetako langa Uharte Arakilgo toponimian.

(13-14-15-16) Aizurdingaña. Ez da ageri toponimia ofizialean ez Uharte Arakilen, ez Aralarren. Osagaiak begi bistakoak: (b)aitz + urdin + -gain + -a. Haitzurdin hitza hargorra (kare-haitza) adierazteko erabiltzen da. Euskaltzaindiaren Hiztegian, haitzurdin marmola adierazteko erabili behar dela dio.

(1-2) Luzanbideco larrea. Aralarko toponimian, Luzanbide eta Luzanbideko larrea. Osagaiak, begi bistakoak, luze eta bide, baina tarteko kontsonante sudurkariak toponimian ezaguna den erlatiboa erabili dela pentsaraz dezake: $\operatorname{luz}(e)^{12}+(d e) n+b i d e+-a$. Errazkingo lehen mugarriak.

(3-4)(1) Surbicelay. Aralarko toponimian jasoa, baina hizpide dugun dokumentuan du erreferentzia bakarra. Osagaiei dagokienez, azken biak baino ez daude nahiko seguru: $b i$ eta zelai. Lehena, agian, $s u(d u) r$, horrela gauzatzen baita, sinkopaturik, aurpegiko apendizearen izena gure eremu guztian. Beraz, bi apendize geografiko dituen zelaia adieraziko luke. Errazkingo azken mugarria eta Beteluko lehena toponimo honen eremuan zegoen.

(2-3-4-) (1) Algortakogaña. Algorta eta Algortako gaina Aralarko toponiman, baina bigarren hori mugarritze honetan soilik. Algorta Malloetako ekialdeko muturrean dagoela dio NTMk, eta 1228 m-ko altuera duela. Osagaiak, beharbada, (b)ar(ri) + go(go) $r+-(e)$ ta dira, $/ \mathrm{r} />/ 1 /$ txandaketa eginik, edo zergatik ez pentsatu bigarren eta hirugarren osagaiak bateginik korta eratzen dela? Beteluko laugarrena eta Intzako lehena ere bai.

(2-3) Atillun. Aralarko toponimian, baina solik mugarritze honetako erreferentziarekin. Ate + illun dira seguru asko bere osagaiak.

(4-5) Fallita. Aralarko toponimian, baina, beste behin, soilik mugarritze hone$\tan$.

(6) Illutico arrate. Aralarko toponimian, mugarritze honetako erreferentziarekin soilik. Bigarren osagaia baino ez da begi bistakoa: (h)arr(i) + ate $+-a$.

12 /a/ konposizioan. 
(7) Aguerdico zuloa. Hau ere Aralarko toponimian, hemengo lekukotza bakarrarekin. Toponimoaren osagaiak honako hauek dira seguru asko: ager $(r i)^{13}+-d i+-k o+$ $z u l o+-a$. Leku ireki edo ez ezkutua behintzat, eta nora begira dagoen adieraziko liguke lehen osagaiak.

(8) Atallorbe. Aralarko toponimian, Atallaurre, baina mugarritze honetako moduan soilik dokumentatu da. Osagaiak, seguru asko, Atall(o) + aurre dira.

(9) Atallorbegaña. Aurrekoaren gainaldea.

(10) Arrigorrituaga. Horrela Aralarko toponimian, erreferentzia bakar honekin atzera berriz, «las piedras enrojecidas» itzulpena eta guzti.

(11) Usalbide aguerria. Aurrekoa bezala. Osagaiak, agian, $u(r)+z a(b a) l+b i d e+$ agerri + - a dira, edo, besterik gabe, uso + ar, $1 / \mathrm{r}$ txandaketa eginik. Begien bistan dagoen ur-korrontea, orduan, edo ageriko eta ohiko uso arren bidea (uso-pasea), apika. Mugarrichuri toponimoa ere ageri da.

(12-13) Aracerteguia. Aralarko toponimian hau ere, dokumentu honetako erreferentziarekin.

(14) (1) Armuñoa. Aurrekoak bezala dokumentazioari dagokionez. Osagaiak, (b) ar(ri) + muino + -a. Mugaberria. Ez da ageri dokumentaturik, eta osagaiak begi bistakoak dira.

(2-3-4) Sollazgaña. Horrela Aralarko toponimian, baina 1991n dokumentatua. Osagaiak, seguru asko, 1561etik 1564ra bitarteko mugarritzearen kasuan nioen moduan, soil $+-a+-z u$ eta gain $+-a$ izanen genituzke. Lehen osagaiak landaretzarik gabeko eremua adieraziko luke, eta gainerakoak aipatuak ditugu dagoeneko.

Horiek guztiak 1857 ko mugarritzean ageri zaizkigun toponimoak ditugu, baina, lehentxeago esan dugun bezala, Baraibarkoak falta zaizkigu, ez zelako bertako inor agertu ikuskatzea egin behar zutenean. Hala ere, nik Baraibarko lurrak Aralarrekin muga egiten duen eremuetako zortzi toponimo (NTM XII) izan ditut kontuan:

Posteroko haitz. Aralarko eta Uharte Arakilgo toponimian, horrelaxe, eta Posteroko haitzeko lezea ere bai azken horretan. Barranca-Burundan, Postekoaitze. Uharte Arakilen hiru modutara ahoskatzen dutela dago jasorik NTMn (posterokuaitz, posterukuaitz, borturokueitz), eta horietako azkenak pentsarazten dit portura edo postura izan dezakeela jatorrian toponimoak. Lehena izanez gero, oso begi bistakoa litzateke esanahia, eta bigarrena, aldiz, ehizarekin lot liteke, ehiza-postua adieraziz.

13 Euskaltzaindiaren Hiztegian bada agerri (adj. Zah. markarekin), eta ageria adierazten duela dio. 
Urdanasko malkorra. Uharte Arakilgo toponimian, Urdenats, Urdenazabal, Urdenasdeneko treguarria, Urdenasko uspela.

Ganbara. Aralarko toponimian, horrelaxe, eta ez dakar inolako iruzkinik. Ganbara etxeen goiko solairua izaten da.

Iraiztaintzeta. Baraibarko toponimian, horrela.

Amurutxate. Aralarko toponimian, Amurutxateko arrasoa/bidea/koba, baina amutxateko ahoskaturik.

Biosna. Aralarko toponimian, Bioznako iturria.

Putxondegi. Aralarko toponimian, horrelaxe. Putzuen tokia adieraziko luke, seguru asko.

Arriolatz. Baraibarko toponimian. Osagaiak, agian, (b)arri + olatz, harrizko korta edo saroia adieraziz.

\section{ARALAR MENDIA 1561ETIK 1564RA BITARTEKO ETA 1857KO MUGARRITZEEN ARABERA MUGATURIK}

Jarraian jasotako mapa 1561etik 1564ra bitarteko mugarritzean (1523koa funtsean) eta 1857 koan ageri zaizkigun mugarri guztiak kontuan harturik bete dut, Aralarrekin muga egiten duten herrietako mugarrien balizko kokapenarekin eta aipatu dokumentuetan horiek dauzkaten izenekin (Baraibarkoak egungo toponimia ofizialetik hartu eta kokatu ditut, gutxi gorabeherako zehaztasunarekin). Guztira 97 mugarri dira, horietako 89 aipatu bi dokumentuetatik eta 8 NTM XIItik jasoak (Baraibar egungo toponimia ofizialaren arabera). Berez, mugarriak zortzi gutxiago dira, herri baten eremuko azkena hurrengo herriko eremuaren lehena delako eta dokumentuetan herri baten azkena eta hurrengoaren lehena jasotzen direlako. Eta hori Baraibarko hasierakoa eta amaierakoa kontuan izan gabe.

Beste alde batetik, zenbait toponimoren eremuan mugarri bat baino gehiago ager daiteke, eta, era berean, mugarri baten kokapenean toponimo bat baino gehiago dago aipaturik dokumentuetan. Mugarriak adierazten dituzten zenbakiak erlojuaren orratzen kontrako norabidea jarraiturik eta mapako iparraldeko Irumugarrietatik hasita daude jarririk.

Mugarriek mapan duten kokapena, bistan da, ez da batere zehatza, norabidearen eta mapako espazioaren arabera erabakitakoa baizik.

Bestalde, esan behar dut mapa Rafael Carasatorre historialari etxarriarrak XX. mendeko laurogeita hamarreko hamarkadan multikopistaz argitaratutako berrogei orrialdeko Unión de Aralar lanetik atera dudala eta lan horretako aurkibidean, 16. atal moduan, honelaxe dagoela aipaturik: «Mapa del ordenamiento forestal». 
Bertan, eskuz idatzita, Aralarko eremuaren inguruan, erlojuaren orratzen kontrako norabidean eta iparraldetik hasita, honako hauek datoz: Uniones Amezketa y Villafranca, T. ${ }^{14}$ Etxarri Lizarrengo, T. Unanua, T. Lizarraga, T. Arbizu, T. Lakunza, T. Arruazu, T. Uharte-Arakil, San Miguel (bidea), T. Baraibar (2 aldiz, bata bidea), T. Errazkin, T. Betelu, T. Valle de Araiz.

Eta, horiez gain, ezkerrean beheko aldean, maparen barnean ageri diren hizki larri zein arruntek eta zenbakiek zer adierazten duten ageri da: "Secciones: A-B-C», «Tramos: 1-2-3-4-5-» eta «Subtramos: a-b-c-».

Eta, azkenik, mapan bertan ere, Aralarren erreferente diren bederatzi toponimo: Irumugarrieta, Errenaga, Putterri, Eulatz, Guardetxe, Aizurdingaña, Beloki, Txemiñe eta Unakoputzu.

Mapan agertzen den gainerako informazioa neuk bertan jarria da, betiere 1561etik 1564ra bitarteko (funtsean 1523koa) eta 1857ko mugarritzeek esaten dutena kontuan izanda, Baraibarri dagokion eremukoa izan ezik.

14 «» horiek, seguru asko, «término» adierazten dute.

118 Cuadernos de Etnología y Etnografía de Navarra (CEEN), 94, 2020, 99-133

ISSN: 0590-1871 ISSN-e: 2530-5840 ISSN-L: 0590-1871 


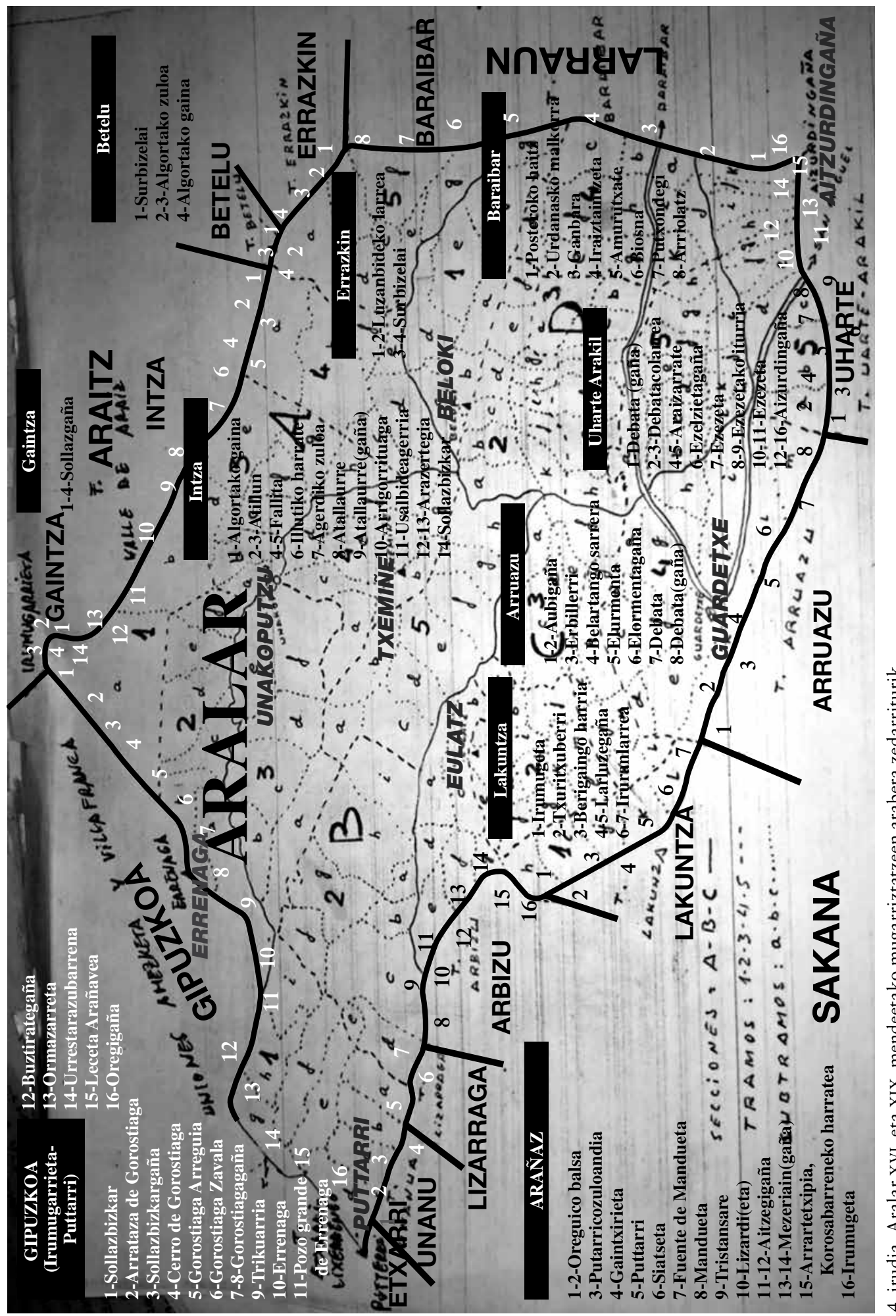




\section{ERREFERENTZIAK}

\subsection{Bibliografia}

Arin Dorronsoro, J. (1928). Toponimia del pueblo de Ataun, Anuario de la Sociedad de Eusko-Folklore (8). Eusko Ikaskuntza, 55-151.

Belasko Ortega, M. (2000). Diccionario etimológico de los nombres de los montes y ríos de Navarra. Iruña: Pamiela.

Benítez Aguado, E. (2007). Deslinde y amojonamiento de términos municipales, CT: Catastro, 60.

Carasatorre Vidaurre, R. (1987-9). Union de Aralar (multikopistaz argitaratutako lana).

Erdozia Mauleon, J. L. (2017a). Auzia Aranatzen XVI. mendean: herri-lurrak, kontzeju edo batzarrak eta zenbait datu onomastiko eta geografiko, Principe de Viana, 269.

Erdozia Mauleon, J. L. (2017b). Euskal toponimo zenbaiten ingurumarian. Euskera, 62(2), 249-288.

Erdozia Mauleon, J. L. (2019). Etxarri Aranazko leku-izenak herrigune historikotik kanpo (Egungo toponimia ofiziala). Iruña: Nafarroako Gobernua.

NTM VIII = Jimeno Jurío, J. M. et al. (1992a). Nafarroako Toponimia eta Mapagin$t z a$, VIII. Iruña: Nafarroako Gobernua.

NTM X = Jimeno Jurío, J. M. et al. (1992b). Nafarroako Toponimia eta Mapagintza, X. Iruña: Nafarroako Gobernua.

NTM XII = Jimeno Jurío, J. M. et al. (1993). Nafarroako Toponimia eta Mapagintza, XII. Iruña: Nafarroako Gobernua.

\subsection{Etxarri Aranazko artxiboko erreferentziak}

Etxarri Aranazko Udal Artxiboa. (1561-1564). Comprende los autos de Amojonamiento desde Soilas bizcar hasta Oregui gaña entre el Sr. Marques de Valmediano y los pueblos de Amezqueta y Abalcizquieta, Legajo núm. 9.

Etxarri Aranazko Udal Artxiboa (1571-1572). Información testifical y auto de amojonamiento con el Sr. Marques de Valmediano.

Etxarri Aranazko Udal Artxiboa (1699). Comprende los autos de amojonamiento del monte de Arizalco, Bargas, Beriain, y Sel de Uzuar. Legajo 1, núm. 5.

Etxarri Aranazko Udal Artxiboa (1739). Autos de amojonamiento de la mojonera de los terminos de Arranaz otorgados por esta comunidad y las villas de Lacunza y Huarte Araquil.

Etxarri Aranazko Udal Artxiboa (1777). Documento n. ${ }^{\circ} 9$ del inventario correspondiente a la Comunidad de Arañaz. Comprende el auto de colocación del mojon de Yrumugueta verificado por la Comunidad de Arañaz, valle de la Burunda y el Sr. Marques de Valmediano.

Etxarri Aranazko Udal Artxiboa (1852). Documento n. ${ }^{\circ} 19$ del inventario correspondiente a la Comunidad de Arañaz. Comprende el auto de reconocimiento y colocación de mojones en los parajes de Arnaz y Ondaz. Legajo núm. 1. 
Etxarri Aranazko Udal Artxiboa (1857). Documento $n .^{\circ} 12$ del inventario correspondiente a la Faceria de Aralar. Comprende el reconocimiento de la mojonera de dicha faceria entre el Real Patrimonio y los congozantes en la misma. Legajo núm. 161.

Etxarri Aranazko Udal Artxiboa (1889). Documento $n . .^{\circ} 24$ del inventario correspondiente a la Villa, Comprende amojonamiento asociado entre Echarri Aranaz y Bacaicoa.

\subsection{Erreferentzia elektronikoak}

https://documentanavarra.blogspot.com

www.enciclopedia-juridica.com

https://dle.rae.es

\section{ERANSKINAK}

Jarraian artikuluan zehar aipatu eta Aralar mendiaren eremua zehazten duten Etxarri Aranazko Udal Artxiboko bi dokumentuen transkripzioa aurkeztuko dut. Transkripzio literala egin dut, hau da, hitzez hitz eta hizkiz hizki jaso dut horietan idatzita dagoena, baina horietan agertzen diren euskal toponimoak hizki etzanez eman ditut gainerako testutik nabarmentzeko. Bestalde, parentesi artean agertzen den guztia nik neuk erantsia da. Batzuetan, dokumentuetan laburturik agertzen diren zenbait hitzen ulermena hobetzeko asmoarekin, hitzak osatu egin ditu nik neuk interpretatu ditudan moduan; beste batzuetan, berriz, mugarri bakoitzaren eremua begien aurrean hobeki finkatzeko, parentesi arteko zenbaki bidez lagundu ditut mugarrien eremu horiek.

\section{1. eranskina: transkripzioa ${ }^{15}$}

Autos de Amojonamiento desde Soilas bizcar hasta Oregui gaña entre el Sr. Marques de Valmediano y los pueblos de Amezqueta y Abalcizquieta», 1561-1564.

En el pleyto litigado por Don Felipe de Lazcano y la Universidad de Ataun con las Universidades de Amezqueta y Abalcizqueta y sus consortes desde 1561 hasta 1564 acumulado al de división de Agaunza se halla la escritura de transacion, sentencia arbitraria y amojonamientos de términos (h)echa y executada por mandado de Juan Martinez de Andueza dueño de la casa de Andueza y el comendador Ochoa Alvarez de Ysasaga jueces compromisarios nombrados precedida citación a Nicolas de Gongora Patrimonial de Navarra a los concejos de Echarri Aranaz, Valle de Araiz y Villas de Villafranca, Tolosa y demas interesados hecha con despacho de 16 de Junio de 1523 refrendada de Garcia Ysasaga escribano mediante facultad que se les tenia concedida por ser para ello y con asistencia del Lizenciado Calderon correxidor de

15 Gogoratu parentesi arteko zenbakiak neuk jarriak direla. 
Guipuzcoa y juntos dichos señores comisionados en el confin del reino de Navarra y de Guip (uzco)a en Goromaga a 3 de Junio de dicho año de 1523 ante Pedro Oynaz escribano de SM habitante en Araiz y Garcia de Ysasaga escribano de SM y del numero de Villafranca en presencia de Juan de Erasqui teniente Patrimonial por Nicolas de Gongora y demas interesados mandaron recibir información de testigos sobre estos dichos limites y recibida la que cada parte dio fallaron como se sigue=

Fallamos que debemos declarar que todos los términos e Pastos que caen e incluyen debajo de los nombres e sitios que debajo serán especificados y declarados sean habidos y tenidos por términos diferenciados sobre que han sido las dichas diferencias pleytos e cuestiones y prendas y carneamientos e cuentos y represalias y por tales los declaramos como de yuso será contenido con que mandamos poner en nuestra presencia y de las dichas partes empezando desde lo cavero encima de Aralar los mojones siguientes $=$

(1) Hallamos ${ }^{16}$ puesto el mojon bajo de Soilas Vizcar que arriba en la cumbre de la dicha Sierra encima del cruz (?) inclusive a consentimiento de todas las dichas partes, damos el mojon por bueno.

(2-3) Yt(em):17 La Arrataza de Gorostiaga entre los dos Cerros de Soilas pusimos un mojon e mas adelante hallamos otro en el Arrataza de Soilaç Vizcarbarrena ${ }^{18} \mathrm{y}$ examinado y con consentimiento de todas las dichas partes damos lo por bueno.

(4) Yt(em):19 Pusimos otro mojon nuevo en el Cerro de Gorostiaga y espuesta a consentimiento de las dichas partes.

(5) Yt(em): ${ }^{20}$ pusimos otro mojon en el lugar llamado Gorostiaga Arregia asi bien a consentimiento de las dichas partes.

(6) Yt(em):21 pusimos otro mojon en el llano de Gorostiagazavala a consentimiento de las dichas partes.

(7-8) Yt(em):22 Hallamos un mojon en Gorostiagagaña y porque era pequeño sacando aquel pusimos otro nuevo a consentimiento de las dichas partes.

16 Orrialdearen ezker aldeko ertzean: Soilaç Vizcar.

17 Ezker aldeko ertzean: Arrate de Gorostiaga.

18 Ezker aldeko ertzean Soilas Vizcarbarrena.

19 Ezker aldeko ertzean: Cerro de Gorostiaga.

20 Ezker aldeko ertzean: Gorostiaga Arreguia.

21 Ezker aldeko ertzean: Gorostiaga Zavala.

22 Ezker aldeko ertzean: Gorostiagagaña.

122 Cuadernos de Etnología y Etnografía de Navarra (CEEN), 94, 2020, 99-133

ISSN: 0590-1871 ISSN-e: 2530-5840 ISSN-L: 0590-1871 
(9-10) Yt(em): habiendo información y usando de nuevo poder pusimos otro mojon en el Cerro de Gorostiaga y otro mojon cortando ${ }^{23}$ de allí al Cerro de Tricuarriy porque entre los dichos dos mojones esta una oya sobre que solia haber gran diferencia que se llama el Suzon de Elordi Elusa declaramos e mandamos que desde los dichos dos mojones puestos hasta el camino que desciende desde dicho Cerro de Gorostiaga pazcan los ganados de dicha Provincia y en siguiente los ganados de Navarra hasta la Peña Verga que esta en cavo de la oya hacia la dicha Provincia sin contradicion ninguna e que por ello no sean prendados por los unos ni los otros, y que el dicho mojon Tricuarria corte hasta el mojon viejo de Errenaga, y declaramos y mandamos que pazcan los ganados de ambas las dichas partes sin contradicion de ninguna persona las yerbas de entre los dichos dos mojones de Errenaga y el Cerro de Tricuarria hasta la piedra de Tricuarria como lo han usado y acostumbrado por que es paso de los ganados.

(11) Yt(em):24 habiendo información pusimos otro mojon en la punta del pozo grande de Errenaga que corta allí desde el mojon biejo de Errenaga cortando entre medias por lo llano como va el camino.

(12) Yt(em):25 seguimos otro mojon en el Cerro grande llamado Buztizategaña en medio de lo llano y declaramos y mandamos que desde el dicho mojon de Buztizategaña que corta el mojon de la punta del pozo que pazcan los ganados de Navarra en la oia que esta pegante hasta el llano de Errenagachiquia sin contradicion ninguna y en siguiente de la otra parte de hacia Navarra desde los dichos mojones pazcan los ganados de la dicha Provincia otro tanto por quanto se suelta desde los mojones hasta Errenagachipia (sic) y en siguiente desde la punta del pozo hasta el mojon viejo de Errenaga y por el llano de la cumbre que le hace entre medias como han acostumbrado por que es paso.

(13-14) Yt(em): pusimos otro mojon mas adelante en otra punta del cerro de Buztizate que va por la cumbre hacia Ormazarreta ${ }^{26}$ y desde allí contra el dicho mojon por las cumbres hasta el llano llamado Urrestarazubarrena ${ }^{27}$ lugar contencioso donde pusimos un mojon en el llano que hace un pradito pequeño y declaramos y mandamos porque es paso de los ganados que gozen y pasen e pazcan los dichos ganados de la una parte y otra en dicho pradito sin contradicion ni prendamiento alguno. Y asi bien mandamos que desde dicho llano de Urrestarazubarrena hasta el cerro grande de Buztizategaña por encima de la cumbre se entienda por mojon las cumbres aguas vertientes como han acostumbrado.

23 Ezker aldeko ertzean: Tricuarri.

24 Ezker aldeko ertzean: Pzo grande de Errenaga.

25 Ezker aldeko ertzean: Bustizategaña.

26 Ezker aldeko ertzean: Hacia Ormazarreta.

27 Ezker aldeko ertzean: Urrestarazubarrena en el supuesto realengo. 
(15-16) Yt(em): ${ }^{28}$ pusimos otro mojon en Leceta Arañava y desde allí corta el dicho mojon la Punta de Aqueaz y desde allí adelante por la cumbre de la Peña de Aguas vertientes hasta dicho llano de Urrestarazubarrena donde pusimos el mojon arriba dicho y desde dicho mojon de Leceta Aranavea a la parte de abajo contra lindea a Oreguigaña ${ }^{29}$ donde pusimos otro mojon desde allí hasta confinar con el mojon de Echarri por las cumbres Aguas vertientes.

Habiendose solicitado de parte de Navarra que el confin se diria desde Allecogaña y desde allí a la Ydoya cortando por Ascoagaña mostrándoles por limites ciertas Ayas y Robles descortezados y los de la dicha Provincia les mostraron desde Allecogaña de entre medios tres mojones diciendo que aquellos eran de entre Navarra y Guipuzcoa.

Fallaron que se pusiese un mojon encima del Cerro de Allecogaña en frente de la Aya ${ }^{30}$ grande y otro mojon al Pie del Roble de tres puas a donde les mostraron un mojon en una sazon mas bajo al pie de una Aya que es la canal encima y otro mojon mas abaxo en un llano devajo al camino donde las mostarron el tercer mojon y otro mojon abajo en la sazonada de Salaceratea los quales mojones cortan e lindan desde Allecogaña de Ascoagaña como van los dichos mojones e limites entre Navarra y Guipuzcoa; y por quanto sobre el dicho temino de alleco no pudieron concertarse a menos que quedase por comunero enq(uadra)do a la prestación de comer las yervas e beber las aguas con sus ganados de sol a sol y que con esta condición hiciesen el amojonamiento y la parte de la Provincia dijo era suyo propio y dejando el gozamiento de la prestacion a la parte de Navarra que a ellos no les quedaría ningún fruto ni provecho que no censentian y dichos jueces acordaron que hasta que S(u) M(agestad) declarase sobre el dicho termino contencioso que asi amojonaron que quedase en el mismo ser que hasta entonces sin que ninguna de las partes aprovechase y hicieron y declararon sobre que las jurisdicciones de los mojones hacia Guipuzcoa fuesen de los s(eñor)es a(lmiran)t(e)s de mis pueblos; cuya sentencia pronunciaron en Alleco a 7 de julio de 1523 ante Pedro de Ugarte es(criba)no de s(ecreta)r(i)o vez(in)o del Lugar de Lizarraga y d(ic)ho Garcia de Ysasaga, y se notifico a todos los interesados.»

Y los de Echarri y su comunidad volvieron a requerir a los dichos jueces para que determinasen lo conducente sobre el termino litigioso de Alleco, pero nada resolvieron y asi se finalizo en 12 de Agosto de 1523.

Es copia fe haciente sacada de la Numeria de Villafranca la presentada en Valladolid y tal vez se hallara la sentencia original en Villafranca y contiene pasadas de cincuenta (h) ojas.»

28 Ezker aldeko ertzean: Leceta Arañava o Aguinaga.

29 Ezker aldeko ertzean: Oreguigaña. Eta horren azpian: Echarr ${ }^{z}$.

30 Horrela, hasierako hizki larriaz.

124 Cuadernos de Etnología y Etnografía de Navarra (CEEN), 94, 2020, 99-133

ISSN: 0590-1871 ISSN-e: 2530-5840 ISSN-L: 0590-1871 


\title{
2. eranskina: transkripzioa (gogoratu parentesi artekoak neuk erantsiak direla)
}

\author{
"Faceria de Aralar. Comprende el reconocimiento de la mojonera de dicha faceria \\ entre el Real Patrimonio y los congozantes en la misma». 1857.
}

«En el monte denominado de Oreguigana jurisdiccion de la Comunidad denominada de Arañaz a veinte y siete de Agosto de mil ochocientos cincuenta y siete ante mi el escribano real y testigos infrascritos es presente de la una parte el licenciado D. Baso Albarez de Carballo, abogado de los Tribunales Nacionales y consultor del Real Patrimonio o su subdelegado en esta provincia en representacion de este sr. y de la otra D. Martin Artieda alcalde de la villa de Echarri aranaz, Jose Erdocia y Miguel Jose Huici regidores de la propia villa, Matias Lizarraga alcalde del valle de Ergoyena, Martin Yjurco regidor del lugar de Lizarraga y D Jose Martin Iriarte alcalde de la villa de Arbizu, en representación de la citada Comunidad de Arañaz, Isidro Garciandia alcalde de la villa de Lacunza, en la de la misma, Gabriel Cristobalena en la de la villa de Arruazu, D. Francisco Yeregui alcalde de la villa de Betelu, Martin Vicente Otermin vecino del lugar de Gainza, Martin Jose Martinicorena vecino del de Errazquin, estos en representacion de los pueblos de Arriba, Atallo, Azcarate, Uztegui, Gainza, Ynza, Errazquin y la citada villa de Betelu como comisionados nombrados por ellas para lo que abajo se espresara y estando asi reunidos por testimonio de mi el dicho escribano propuso el mencionado señor consultor que el año de mil seiscientos ochenta y seis se verifico el amojonamiento de los Montes reales de Aralar por el Sr. D. Geronimo Elordi y pueblos limitrofes a ellos con citacion y asistencia de sus representantes y de los demas pueblos congozantes de aquellos y aunque a pocos años se realizo la verificacion del mencionado amojonamiento por el Sr. Borda y Goyeneche. Los pueblos carecen de este documento por ignorar su paradero, aunque el mencionado Sr. consultor manifesto que debia obrar en la secretaria o archivo de la Excelentisima Diputacion Provincial de Navarra, aunque pendiente por haber suplicado algunos pueblos con nulidades y agravios de la indicada rectificacion y como desde entonces nada se ha verificado del insinuado amojonamiento, se ignora si con el discurso de tantos años han desaparecido algunos de los mojones colocados y con el deseo de cortar todo motivo de disensiones y disturbios entre los pueblos limitrofes a los mencionados Reales Montes y los demas que tienen sus goces en ellos y el real patrimonio a quien pertenece su propiedad les hizo ver los deseos que tenia de que se ejecutase un formal reconocimiento de la indicada mojonera, en que convinieron tambien dichos pueblos y con ese fin se han reunido en el dia de hoy en este citado paraje del...

(Ez dago etenik transkripzioan, baina ohar hau egiten dut azaltzeko mugarrien zenbakiak orrialdearen ezkerraldean ageri direla).

1. ....alto de Oreguicobalsa en donde se halló el mojon que espresa el auto de amojonamiento el cual divide los Montes Reales de Aralar, los de la Provincia de Guipuzcoa que quedan por la parte del norte, y por el poniente los de la Comunidad de Arañaz que fue el primero que se reconoció. 
2. Siguiendo hacia el oriente por el mismo cerro de Oreguicobalsa se halló a poca distancia el segundo mojón.

3. Continuando en dirección para la peña de Putarri en la oyada que sale de Putarricozuloandia en el mismo ahugero se halló este tercer mojon conforme espresa el último amojonamiento.

4. Siguiendo en esta diligencia habiendo pasado el parage denominado de Gainchiquieta se encontró este mojón en tierra rancado de su sitio y tirado a la parte de los montes de dicha Comunidad, y en atención a que del parage donde se encuentra dicho mojon no se puede rancar por ser inaccesible, convienen y conforman en que un representante de la propia Comunidad y del sobreguarda haciéndose uno nuevo se coloque donde existía el anterior, cuyo sitio está bien conocido.

5. Subiendo al mismo alto de la peña llamada de Putarri se halló este mojón.

6. Bajando de la citada peña mirando al oriente se encontró este mojón en el sitio llamado Siasbelceta.

7. Continuando en la misma dirección del oriente, se halló este mojon cerca de la fuente de Mandueta entre esta y la de Siasbelceta en el alto que existe entre las dos fuentes.

8. Siguiendo la propia dirección se encuentra este mojón en el parage llamado Mandueta.

9. Prosiguiendo en la misma dirección del oriente y llegando al alto de Tristansare cerca de la nebera natural (Elurzulota) quedando esta a la parte de Aralar se encuentra este mojón.

10. A poca distancia del anterior mojón se halló el mojón diez frente a la peña llamada Lizardi..

11., 12., 13. y 14. Continuando en la misma dirección y pasando al sitio denominado de Aiceguigaña o Meceriangaña en el mismo alto aguas vertientes, donde dicho auto de amojonamiento del s(eño)r. Elordi dice había unas ayas cortadas y blanqueadas, se encuentran en muy poca distancia cuatro mojones los cuales dieron por legitimos.

15. Prosiguiendo según dice el cerro y peña tajada según menciona el último amojonamiento del s(eño)r. Elordi por las aguas vertientes hasta el portillo mas abajo de Arrartechipia o erchia de Corosabarren, se halló este mojón conforme menciona el indicado amojonamiento.

16. Continuando para abajo y a poca distancia a la mano izquierda del citado camino que baja de Corosabarren se halla este mojón en el parage llamado Yrumugueta en donde existen dos mojones, el uno para dividir la jurisdicción de la citada Comunidad con Aralar y el otro con la villa... 
(Lacunza jartzen du ezkerraldean, herri horrekiko mugarritzea hasten dela jakinarazteko)

1. ...de Lacunza para cuyo pueblo es el primer mojón.

2. Siguiendo el citado camino para abajo a corta distancia a mano izquierda del citado camino a la entrada de Churuchuberri se halló este mojón.

3. Bajando la citada linea se encontró este mojón en el parage llamado Beraingoarria.

4. Continuando la diligencia de revisión se encontró este mojón a la vista del sitio que llaman Larlucegaña.

5. Siguiendo dicha linea para abajo se encontro este mojon en la punta de un despeñadero que va hacia dicho sitio de Larlucegaña, el cual se encuentra tirado, y acuerdan se coloque en su sitio por un representatnte de la citada villa de Lacunza y otro del Real Patrimonio.

6. Bajando del ultimo mojon y atravesando un barranco y bosque en el parage llamado Irucilachiquita se hallo este mojon.

7. Siguiendo por dicho parage de Irucilachiquita mas adelante en el sitio del mismo nombre de Irucilachiquita se halla este mojon que es el ultimo de la jurisdiccion de la mencionada villa de Lacunza, entrando por consicuiente en la jurisdicción de la villa de Arruazu.

(Arruazu jartzen du, orrialdearen ezkerraldean).

1. El primer mojon con esta villa y Aralar se encontró en el parage denominado de Aubiagaña en lugar de Iruranlarrea que espresa dicho ultimo amojonamiento, cuyo parage de Aubiagaña viene siguiendo la linea del ultimo mojon de Lacunza y sitio de Larrelucegaña.

2. Siguiendo por el mismo termino de Aubiagaña hacia el oriente se encontró el segundo mojon a distancia como de cuatrocientas a quinientas varas.

3. Continuando la misma linea recta hacia el poniente se encontro este mojon en el parage denominado Ervillarri.

4. Prosiguiendo la propia linea recta hacia el oriente se hallo este mojon en el parage que llaman Belaztangoentrada.

5. Siguiendo dicha linea recta hacia el espresado lado de oriente y llegando al parage de Elormenta en lugar de Orormendigaña que indica dicho ultimo auto de amojonamiento se encontro este mojon. 
6. Prosiguiendo linea recta hacia dicha parte del oriente, llegando al sitio conocido por Elormentagaña se hallo este mojon, previniendo que del anterior mojon como a treinta y seis pasos de distancia se halla el ahugero que se llama Geltilarri, en lugar de Aragoarria que menciona el auto del ultimo amojonamiento.

7. Continuando la propia linea recta hacia dicha parte del oriente, llegando al parage de Debata se encontró este mojon.

8. Prosiguiendo la misma linea recta hacia el oriente en el alto denominado Debatagaña se encontro este mojon, con los que se da fin a la jurisdicción de la citada villa de Arruazu y montes reales de Aralar, previniendo que con el discurso del tiempo que ha mediado desde qu ese ejecutó el amojonamiento del S(eño)r. Elordi del año mil seiscientos ochenta y seis, han cambiado los nombres de los sitios donde se colocaron dichos mojones, especialmente en la jurisdicción de la mencionada villa de Arruazu y montes reales de Aralar, adviertiendo asi mismo que el llevar como llevan los citados mojones de la citada jurisdicción de Arruazu la letra La consiste en que al tiempo de su colocación era comun dicha villa con la de Lacunza ${ }^{31}$ con lo que se suspendio la diligencia por no permitir el dia, habiendo asistido a ella a mas de los señores que se llevan arriba mencionados D. Ignacio Cia tambien escribano publico, de parte de la villa de Irañeta y pueblos de Yabar y Villanueva. De que mandaron hacer este auto que firmaron los que dijeron sabian y en su fe lo hice yo el escribano, siendo testigos Jose Angel Mariezcurrena y Miguel Sebastian Echarri vecinos de dicha villa de Echarri aranaz, que solo firmo el primero y no el segundo porque dijo no sabia = Martin Artieda = L. Basa Albarez de Carballo $=$ Matias Lizarraga $=$ Jose Martin Iriarte = Martin Ijurco =Jose Francisco Yeregui $=$ Martin Jose Martinicorena = Isidro Garciandia $=$ Gabriel Cristobalena =Ignacio Cia = Jose Angel Mariezcurrena = ante mi Martin Francisco Saralegui escribano =

\section{(Jarraian hasten da Uharte Arakilgo eremua).}

En el parage llamado Debatagaña, juristdiccion de la villa de Huarte Araquil y Reales Montes de Aralar a veinte y ocho de Agosto de mil ochocientos cincuenta y siete ante mi el escribano real y testigos infrascritos son presentes de la una parte el S. D. Basa Albarez de Carballo, consultor del s. Subdelegado del Real Patrimonio en esta Provincia, y de la otra D. Miguel Francisco Irañeta, alcalde, Jose Vicente Fernandino, regidor, Domingo Razquin y Leon Gorriti, vecinos de la villa de Huarte Araquil en representacion de la propia villa, Martin Artieda, Matias Lizarraga y D. Jose Matin Iriarte en representacion de los pueblos de la Comunidad de Arañaz, Gabriel Betelu en la de la villa de Arruazu, D. Ignacio Cia en el de la villa de Irañeta y pueblos de Yabar y Villanueva, D. Francisco Yeregui, Martin Vicente Otermin y Martin Jose Martinicorena como representantes de los pueblos del valle de Araiz, villa de Betelu y pueblo de Errazquin y estando asi convocados dijeron que el dia de hoy se han reunido a efectos

31 Esaten ari zaigu XVI. mendearen hasieran Lakuntza eta Arruazu bat zirela. 
de continuar la diligencia de reconocimiento de mojones dejada el dia de ayeren el alto denominado de Debatagaña donde se concluyo la jurisdiccion de la villa de Arruazu con los Montes Reales de Aralar y en el mismo sitio de Debatagaña y proximo al indicado ultimo mojon se hallo...

1. El primero con la citada villa de Huarte Araquil.

2. Bajando del citado parage al llamado de Debatacolarrea en la oyada hacia el oriente se hallo este mojon.

3. Continuando la misma linea y encontrandose con el camino que de Guipuzcoa se sube al santuario de San Miguel de Excelsis se hallo este mojon cerca de dicho camino.

4. Continuando dicho reconocimiento a muy poca distancia se encontro este mojon.

5. Prosiguiendo la linea y a corta distancia se encontro este mojon en el parage llamado Araizarrate.

6. Siguiendo esta diligencia y a poca distancia se hallo este mojon en el parage denominado Ecelcietagaña.

7. Continuando dicha diligencia se hallo este mojon junto al camino carretil de Ecelcieta antes de llegar a él.

8. El octavo mojon se encontró frente a la fuente o gambella de Ecelcieta.

9. A corta distancia del mojon anterior se hallo este a la caida para Aralar.

10. A la misma distancia que del anterior y en el propio parage de Ecelcieta se hallo este mojon.

11. A igual distancia que al anterior poco mas o menos y en el mismo parage se encontro este mojon.

12. Siguiendo dicho reconocimiento por la misma linea de poniente y norte se hallo este mojon.

13. Continuando hasta el llano de Ecelcieta dando vista a Aizurdinñaga (sic) se encontro este mojon.

14. Prosiguiendo hasta dar principio para asubir la cuesta de Aizurdinñaga se encontro este mojon.

15. Subiendo la peña de Aizurdingaña sobre el camino o Arrate de dicho terminose hallo este mojon aguas vertientes. 
16. En lo mas alto de Aizurdiñaga se encontro este mojon siendo este el ultimo de la mojonera con la indicada villa de Huarte Araquil, previniendo que una peña de dicho parage tiene una cruz con lo que se concluyo esta diligencia de reconocimiento con respecto a la propia villa de Huarte Araquil. De que mandaron hacer este auto que firmaron los que dijeron sabian con mi el escribano, doy fe = Martin Artieda $=$ L. Baso Albarez de Carballo = Matias Lizarraga = Jose Martin Iriarte = Miguel Francisco Irañeta = Jose Francisco Yeregui = Martin Josep Martinicorena = Gabriel Cristobalena = Ignacio Cia = Leon Gorriti = Jose Angel Mariezcurrena = Francisco Antonio Lopez de Goicoechea $=$ ante mi Martin Francisco Saralegui escribano = En el parage denominado de Albia jurisdicion del Real Patrimonio dicho dia mes y año: estando reunidos ante mi el escribano real y testigos infrascritos de la una parte el S. D. Baso Albarez de Carballo, y de la otra los Sres. Martin Artieda, Matias Lizarraga y D. Jose Martin iriarte, representantes de los pueblos de la Comunidad de Arañaz, Gabriel Cristobalena que lo es por la villa de Arruazu, D. Ignacio Cia por los de Irañeta, Yabar y Villanueva, D. Francisco yeregui, Martin Vicente Otermin y Martin Josep Martinicorena por los del valle de Araiz, villa de Betelu y lugar de Errazquin, dijeron que con el deseo de verificar igual reconocimiento de mojones que en los demas pueblos con el Baraibar, ha pasado recado verbal a su regidor con un guarda bosques dicho Sr. Consultor, a fin de que saliese a la mojonera del citado pueblo y villa de Huarte Araquil la representacion del mismo pueblo, quienes no han tenido sin duda por conveniente el hacerlo, y en su vista dichos señores determinaron continuar en el citado reconocimiento pasando a ese fin dejando segun queda espresado la jurisdiccion de Baraibar llegaron a la del lugar de Errazquin y parage llamado Luzanvidecolarrea que es un prado raso y sin arboles...

\section{(Errazkingoa hasten da, Baraibarkoak ez zirelako agertu).}

1. ... en el que hallaron un mojon que es el trece de los que vienen del indicado pueblo de Baraibar y primero de este lugar, el cual sirve de tres mojones porque divide las jurisdicciones de este indicado pueblo de Errazquin, el de Baraibar y el de Aralar.

2. El segundo mojon se encontro en el parage que llaman Luzanvidecolarrea.

3. Siguiendo para adelante y pasando al sitio denominado Surbicelai se encontro este mojon el cual asi como el anterior estaban torcidos, y de conformidad de todos fueron enderezados, con lo que se concluyo la jurisdiccion de dicho lugar de Errazquin

4. pasando al mojon cuarto del propio pueblo ...

\section{(Beteluko eremua hasten da).}

1. ... y primero de la villa de Betelu se hallo este mojon en el alto denominado Surbicelay segun espresa el ultimo amojonamiento. 
2. Continuando en esta diligencia marchando al parage denominado Algortacozuloa se encontro este segundo mojon y por hallarse torcido se enderezo de conformidad.

3. Siguiendo este reconocimiento se encontro este tercer mojon en dicho termino en una falda conforme espresa el ultimo amojonamiento.

4. Pasando a este mojon que es el cuarto de dicha villa de Betelu...

\section{(Intzakoekin hasten da).}

1. ...y primero de Inza se hallo en el parage que llaman Algortacogaña conforme menciona el ultimo amojonamiento, y por ser ya pasada la tarde se suspendio hasta el dia de mañana esta diligencia de que mandaron hacer este auto siendo testigos asi en este como en el anterior auto del dia de ayer, Jose Angel Mariezcurrena vecino de la villa de Echarri Aranaz y Francisco Antonio Lopez de Goicoechea guarda bosque, firmaron los que dijeron sabian con mi el escribano doy fe = Martin Artieda = L. Baso Albarez de Carballo = Matias Lizarraga = Jose Martin Iriarte = Jose Francisco Yeregui $=$ Martin Jose Martinicorena $=$ Gabriel Cristobalena $=$ Francisco Antonio Lopez de Goicoechea = Jose Angel Mariezcurrena = ante Martin Francisco Saralegui escribano =

En los Montes Reales de Aralar a veinte y nueve de Agosto de mil ochocientos cincuenta y siete $=$ ante mi el escribano real y testigos infrascritos es presente D. Baso Albarez de Carballo Consultor del real Patrimonio en esta provincia en representacion del mismo y de la otra D Francisco Yeregui alcalde de la villa de Betelu, Martin Vicente Otermin, Martin Jose Martinicorena, Francisco Buldain, Jose Miguel Ciraco y Joaquin Liciaga por los pueblos del valle de Araiz y villa de Betelu, Martin Artieda, Matias Lizarraga y D. Josep Martin Iriarte por la Comunidad de Arañaz, D. Ignacio Cia por los de Irañeta, Yabar y Villanueva y estando asi convocados dijeron que consecuente a lo determinado el dia de ayer...

2. ... se han convocado en el de hoy con el objeto de finalizar el reconociemiento de mojones que tienen principiado y pasando al sitio llamado Atillun pegando al termino que del lugar de Inza se va para Lacunza se encontro el segundo mojon.

3. Pasando por la ladera y cerro muy peñascoso se encontro este mojon segun menciona el anterior amojonamiento.

4. Subiendo otro pequeño cerro pasando por el lado de una cueva estrecha y muy honda se hallo este mojon en el parage llamado Fallita conforme indica dicho ultimo amojonamiento.

5. Continuando dicha mojonera se paso al lado de dicho cerro de Fallita en donde no se encontro este mojon y por esa razon conformaron que con asistencia de dicho pueblo de Inza y un comisionado que señalen los demas pueblos del valle de 
Araiz, Betelu y Errazquin y el sobreguarda o encargado de este se fijo un nuevo mojon en dicho parage.

6. Marchando de dicho parage cuesta abajo atravesando un sendero que van de Inza para Lacunza en el parage llamado Illuticoarrate o Osozulueta se hallo este mojon.

7. Yendo adelante por el cerro arriba en el parage denominado Aguerdicozuloa se hallo este septimo mojon.

8. Subiendo por la cuesta para arriba en el parage de Atallorbe se encontro este mojon.

9. Marchando por una barrancada y subiendo al alto denominado Atallorbegaña andia en un llanito se hallo este mojon.

10. Prosiguiendo para adelante por el cerro llamado Arrigorrituaga se encontro este mojon conforme dice el ultimo amojonamiento.

11. Bajando de este punto a la entrada llamada Usalvide Aguerria o Mugarrichuri se hallo corriente este mojon.

12. Continuando dicha mojonera y pasando al parage de Aracerteguia se encontro este mojon.

13. Siguiendo para adelante hacia la parte del poniente junto al sel donde suele acogerse el ganado menudo de lo realengo se encontro este mojon.

14. Pasando de dicho mojon a Soilas vizcar se encontro el catorce.

Subiendo de este parage a Armuñoa y cerro llamado Arecetagaña se hallaron tres mojones juntos, siendo el de medio el que se conoce con el nombre del Rey y los otros dos de los estremos los de Gainza e Inza , teniendo los de este pueblo segun se manifiesta en el ultimo amojonamiento otros tres mojones en lo realengo.

\section{(Hemen hasten da Gaintzako ikusketa).}

1. Habiendose puesto en la ladera de Arrezaterragaña que en vascuence llaman Mugaberria con este mojon viene a quedar cortado o rodeado el termino de dicho lugar de Inza. Por manera que todo lo que dista desde dichos tres mojones juntos bajando linea ladeada hacia la Sierra de Aralar por el dicho mojon nuevo y el de Armuñoa, lo que mira hacia el dicho cerro de Soilasvizcar queda para el Real Patrimonio.

2. Continuando de dicho parage de Sollazgaña mirando al poniente en el parage de esalde se hallo el segundo mojon de Gainza porque el anterior concluye en la jurisdiccion de Inza y principia con el de Gainza.

132 Cuadernos de Etnología y Etnografía de Navarra (CEEN), 94, 2020, 99-133

ISSN: 0590-1871 ISSN-e: 2530-5840 ISSN-L: 0590-1871 
3. Prosiguiendo hacia el poniente en el parage de se hallo este mojon.

4. Siguiendo hacia Guipuzcoa se hallo otro mojon que es el que concluye con la mojonera de Gainza con lo Realengo de Aralar y Guipuzcoa.

Con lo cual dan por concluido este reconocimiento de las mojoneras de los pueblos limitrofes a la propia sierra, habiendo quedado sin reconocer segun queda espresado la del lugar de Baraibar a causa de no haber salido ningun representante a pesar de habersele avisado, habiendo por legitimos los mojones reconocidoa sin que a dicho Sr. Consultor ni a los representantes de los pueblos les ocurra hacer reclamacion alguna de todo lo cual acordaron hacer este auto siendo testigos Jose angel Mariezcurrena y Francisco Antonio Lopez de Goicoechea, hallados en dicho parage, firmaron los que dijeron sabian con mi el escribano en fe de ello = Martin Artieda = L. Baso Albarez de Carballo $=$ Matias Lizarraga $=$ Jose Martin Iriarte $=$ Francisco Antonio Lopez de Goicoechea = Jose Francisco Yeregui $=$ Martin Jose Martinicorena = Gabriel Cristobalena = Ignacio Cia = Josep Angel Mariezcurrena = Ante mi Martin Francisco Saralegui escribano.»

(Eta hortik aurrera hizki mota aldatzen da eta aurrekoaren egiaztapena da, bigarren kopia moduan, eskribau berak egina hurrengo urtean, 1858ko otsailaren 27an, hamaika lerrotan). 
0000 